\title{
CD9 induces cellular senescence and aggravates atherosclerotic plaque formation
}

\author{
Jung Hee Cho ${ }^{1,2,3} \cdot$ Eok-Cheon Kim ${ }^{1,2} \cdot$ Youlim Son $^{1,2} \cdot$ Da-Woon Lee ${ }^{1,2} \cdot$ Yong Seop Park ${ }^{1,2} \cdot$ Joon Hyuk Choi ${ }^{4}$. \\ Kyung-Hyun $\mathrm{Cho}^{5} \cdot \mathrm{Ki}^{-S u n} \mathrm{Kwon}^{6} \cdot$ Jae-Ryong $\mathrm{Kim}^{1,2}$
}

Received: 5 June 2019 / Revised: 31 March 2020 / Accepted: 1 April 2020 / Published online: 28 April 2020

(c) The Author(s), under exclusive licence to ADMC Associazione Differenziamento e Morte Cellulare 2020

\begin{abstract}
$\mathrm{CD} 9$, a $24 \mathrm{kDa}$ tetraspanin membrane protein, is known to regulate cell adhesion and migration, cancer progression and metastasis, immune and allergic responses, and viral infection. CD9 is upregulated in senescent endothelial cells, neointima hyperplasia, and atherosclerotic plaques. However, its role in cellular senescence and atherosclerosis remains undefined. We investigated the potential mechanism for CD9-mediated cellular senescence and its role in atherosclerotic plaque formation. CD9 knockdown in senescent human umbilical vein endothelial cells significantly rescued senescence phenotypes, while CD9 upregulation in young cells accelerated senescence. CD9 regulated cellular senescence through a phosphatidylinositide 3 kinase-AKT-mTOR-p53 signal pathway. CD9 expression increased in arterial tissues from humans and rats with age, and in atherosclerotic plaques in humans and mice. Anti-mouse CD9 antibody noticeably prevented the formation of atherosclerotic lesions in $\mathrm{ApoE}^{-/-}$mice and $\mathrm{Ldlr}^{-/-}$mice. Furthermore, $\mathrm{CD} 9$ ablation in $A p o E^{-/-}$mice decreased atherosclerotic lesions in aorta and aortic sinus. These results suggest that CD9 plays critical roles in endothelial cell senescence and consequently the pathogenesis of atherosclerosis, implying that CD9 is a novel target for prevention and treatment of vascular aging and atherosclerosis.
\end{abstract}

These authors contributed equally: Jung Hee Cho, Eok-Cheon Kim, Youlim Son

Edited by G. Melino

Supplementary information The online version of this article (https:// doi.org/10.1038/s41418-020-0537-9) contains supplementary material, which is available to authorized users.

$\triangle$ Jae-Ryong Kim

kimjr@ynu.ac.kr

1 Department of Biochemistry and Molecular Biology, Yeungnam University, Daegu 42415, Republic of Korea

2 Smart-aging Convergence Research Center, Yeungnam University, Daegu 42415, Republic of Korea

3 Personalized Genomic Medicine Research Center, Korea Research Institute of Bioscience and Biotechnology, Daejeon 34141, Republic of Korea

4 Department of Pathology, College of Medicine, Yeungnam University, Daegu 42415, Republic of Korea

5 School of Biotechnology, Yeungnam University, Gyeongsan 38541, Republic of Korea

6 Aging Research Center, Korea Research Institute of Bioscience and Biotechnology, Daejeon 34141, Republic of Korea

\section{Introduction}

Cellular senescence is a dynamic process in which cells arrest proliferation. Cellular senescence is induced during embryonic development [1] as well as by diverse stress responses such as telomere attrition, activation or inactivation of oncogenes, loss of tumor suppressor genes, epigenetic alterations, inflammation, oxidative stress, chemotherapeutic agents, and UV irradiation or ionizing radiation [2]. Senescent cells reveal characteristic phenotypic alterations, including flattened and enlarged cell morphology, senescence-associated $\beta$-galactosidase $(\mathrm{SA} \beta \mathrm{G})$ staining, senescence-associated secretory phenotypes, and DNA damage foci in the nucleus [3]. Cellular senescence influences tissue and organismal aging, tissue repair and regeneration, cancer progression and protection, and diverse age-related pathologies, through cell-autonomous and/or non-cell-autonomous mechanisms [4].

Accumulating evidence suggests that vascular cell senescence, including vascular smooth muscle cells (VSMCs) [5] and macrophages [6] contribute to atherosclerosis [7]. Plaque VSMCs showed reduced expression and telomere binding of telomeric repeat-binding factor-2 (TRF2) and transgenic mice expressing VSMC-specific 
TRF2 decreased atherosclerosis and necrotic core areas [5]. Removal of senescent macrophages attenuated atherosclerotic plaque formation in $\mathrm{Ldlr}^{-/-}$backgrounds [6]. However, role of endothelial cell senescence in atherosclerosis remains unclear.

CD9 (TSPAN29) is a $24 \mathrm{kDa}$ tetraspanin protein that contains four putative transmembrane domains, short $\mathrm{N}$ and C-terminal cytoplasmic domains, a small intracellular loop, and two extracellular loops [8]. CD9 is expressed in a wide variety of cell types, including endothelial cells, smooth muscle cells, hematopoietic cells, epithelial cells, and malignant cells [9]. Similar to other tetraspanins, CD9 generally does not function as a cell-surface receptor, but rather as an organizer of multimolecular complexes, including integrins, immunoglobulin superfamily members such as EWI-F and EWI-2, heparin-binding EGF-like growth factor, claudin-1, and other tetraspanins [10]. CD9 plays important roles in cell adhesion and migration [11], platelet activation and aggregation [12], fusion of sperm and ovum during mammalian fertilization [13, 14], cancer progression and metastasis [15, 16], humoral immune response [17], allergic reaction [18], and replication of HIV-1 and influenza viruses [19].

Previously, we reported that CD9 level increased in senescent endothelial cells [20]. CD9 overexpression was observed in VSMCs of neointima hyperplasia and a neutralizing CD9 antibody inhibited neoinitima thickening in a mouse carotid artery ligation model [21], although $C D 9$ knockout mice revealed no difference in smooth muscle cell migration and neointima formation after vascular injury [22]. CD9 expression was also enhanced in human atherosclerotic lesions [23], activated osteoclasts in ovariectomy-induced osteoporosis, and in bone erosions of collagen-induced arthritis [24]. These reports suggest that CD9 might be involved in cellular senescence and atherosclerosis; however, mechanisms by which CD9 regulates these phenomena remain undefined.

In the present study, we investigated the roles of CD9 in cellular senescence using human umbilical vein endothelial cells (HUVECs) and atherosclerosis. We found that $C D 9$ knockdown in senescent cells significantly overcame senescence phenotypes, while $C D 9$ upregulation in young cells induced cellular senescence. Moreover, we demonstrated that CD9 regulates cellular senescence through a PI3K-AKT-mTOR-p53 signal pathway. The levels of CD9 increased in human and rat arterial tissues with age, as well as in human and murine atherosclerotic lesions. The inhibition of CD9 using CD9-specific antibodies significantly ameliorated cellular senescence in vitro, as well as atherosclerotic plaque formation in vivo. In addition, $C D 9$ depletion in $\mathrm{ApoE}^{-/-}$mice decreased atherosclerotic plaque formation.

\section{Materials and methods}

\section{Materials}

HUVECs and endothelial cell basal medium-2 (EBM-2) containing several growth factors were purchased from Lonza Inc. (Walkersville, MD, USA). Dulbecco's modified Eagle medium (DMEM), fetal bovine serum (FBS), $100 \mathrm{U} / \mathrm{ml}$ penicillin, and $100 \mathrm{mg} / \mathrm{ml}$ streptomycin were purchased from Welgene (Daegu, Republic of Korea). The primers used in this study were synthesized by Bioneer Inc. (Daejeon, Republic of Korea) (Supplementary Table 1). The primary antibodies used in this study are listed in Supplementary Table 2. AD293 cells, pShuttle vector, pAdEasy-1 vector, and a pAdEasy titer kit were purchased from Stratagene Corp. (La Jolla, CA, USA). Stealth ${ }^{\mathrm{TM}}$ siRNA for $C D 9, p 53, A T M$, and negative control siRNA were purchased from Invitrogen Life Technologies Inc. (Carlsbad, CA, USA). p16 Silencer $^{\circledR}$ select validated siRNA, PIK3CA Silencer ${ }^{\circledR}$ select validated siRNA, and $P I K 3 C B$ Silencer ${ }^{\circledast}$ select validated siRNA were purchased from Ambion (Carlsbad, CA, USA). Total RNA isolation (TRI) solution was purchased from BioScience Technology (Daegu, Republic of Korea). An agarose gel extraction kit was acquired from SolGent (Daejeon, Republic of Korea). 5-bromo-4-chloro-3-indolyl- $\beta$-D-galactoside (X-gal), LY294002, and rapamycin were purchased from Sigma-Aldrich Chemical Co. (St. Louis, MO, USA). A bromodeoxyuridine (BrdU) flow kit was acquired from BD Biosciences (Cat. no. 552598, San Jose, CA, USA). An FITC-conjugated CRKRLDRNC peptide was kindly donated by B. H. Lee (Kyungpook National University, Daegu, Republic of Korea).

\section{Human arterial tissues and atherosclerotic plaques from carotid arteries}

Human vascular tissues of the spleens and testes from 1 to 90 year olds, grouped by 10 -year age intervals (each, $n=$ $20)$, and human carotid artery tissues $(n=6)$ were obtained from atherosclerosis patients at Yeungnam University Hospital (Daegu, Republic of Korea) consenting to surgical excision from 1995 to 2012 with Internal Review Board approval (YUMC 2015-01-017).

\section{Animal tissues and experiments}

All animal studies were approved by the Institutional Animal Care and Use Committee of the College of Medicine, Yeungnam University (YUMC-AEC2013-008, YUMCEDU2014-014, YUMC-AEC2018-017, YUMC-AEC2018030, and YUMC-AEC2019-029). ApoE ${ }^{-/-}$mice and $\mathrm{Ldll}^{-/-}$mice were kindly donated by G. T. Oh (Ewha Womans University, Seoul, Republic of Korea) and $C D 9^{-/-}$ 
mice by K. Miyado (National Research Institute for Child Health and Development, Tokyo, Japan). CD9 and ApoE double knockout mice were obtained by crossing $C D 9^{-/-}$ and $A p o E^{-/-}$mice. Aortic sinus tissues of $A p o E^{-/-}$mice aged 10, 20, 50, and 100 weeks provided with regular diet were prepared. Heart and aortic tissues of 6- and 24-monthold rats (each, $n=4$ ) were obtained from the Aging Tissue Bank (Pusan, Republic of Korea). To test the effects of a neutralizing CD9 antibody on atherosclerotic lesion formation in $A p o E^{-/-}$mice, male mice were divided into two groups (each, $n=9$ ). Mice were fed rodent diet with $45 \%$ kCal fat (Research Diets Inc., New Brunswick, NJ, USA). One hundred micrograms of rat anti-mouse CD9 monoclonal antibody (KMC8, BD Pharmingen, Cat. no. 553758) or rat $\operatorname{IgG}$ were injected intraperitoneally every 3.5 days for 15 weeks. Male $L d l r^{-/-}$mice were fed rodent diet with $45 \%$ kCal fat (Research Diets Inc., New Brunswick, NJ, USA) for 4 weeks. After diet was changed into normal chow diet, $100 \mu \mathrm{g}$ of rat anti-mouse CD9 monoclonal or rat IgG were injected intraperitoneally every 3.5 days for 6 weeks (each, $n=3$ ). Animals were allocated into groups by simple randomization based on a single sequence of random assignments. Food intake and body weight were measured every 3.5 days. Mice were sacrificed and the formation of atherosclerotic lesions in the aortas and the aortic sinuses were analyzed. Animal experiments were not blinded to the group allocation during the experiments and when assessing the outcome.

\section{Cell culture}

HUVECs were maintained in EBM-2 containing several growth factors. Cells were seeded at $1 \times 10^{5}$ cells per $100 \mathrm{~mm}$ culture dish and incubated under a $5 \% \quad \mathrm{CO}_{2}$ humidified atmosphere at $37^{\circ} \mathrm{C}$. When the cells reached 80-90\% confluence, they were trypsinized and subcultured. The number of population doublings (PDs) was calculated from the geometric equation: $\mathrm{PD}=\log _{2} F / \log _{2} I$, where $F$ is the cell number at the end of incubation time and $I$ is the cell number at the beginning of the incubation time. For all experiments, cells were used after passage $7(\mathrm{PD}<28)$ or passage 15 (PD > 50). In this study, these cells were referred to as "young" or "senescent," respectively.

\section{Adriamycin treatment}

HUVECs $(\mathrm{PD}<28)$ were seeded at $1 \times 10^{5}$ cells in $60 \mathrm{~mm}$ culture dishes and incubated overnight at $37{ }^{\circ} \mathrm{C}$ in a $5 \%$ $\mathrm{CO}_{2}$ humidified incubator. Cells were then washed two times with DMEM containing $1 \%$ antibiotics $(100 \mathrm{U} / \mathrm{ml}$ penicillin and $100 \mu \mathrm{g} / \mathrm{ml}$ streptomycin) and then treated with $500 \mathrm{nM}$ adriamycin for $4 \mathrm{~h}$. After washing, cells were further incubated in culture media for 4 days.

\section{Total RNA extraction}

Total RNA was isolated using TRI solution according to the manufacturer's suggestion. Concentrations of RNA were calculated by measuring the absorbance at $260 \mathrm{~nm}$ using a UV spectrophotometer (Shimadzu, Japan), after which the isolated RNA was stored at $-70^{\circ} \mathrm{C}$ until use.

\section{Reverse transcription-polymerase chain reaction (RT-PCR)}

RT-PCR was conducted using $1 \mu \mathrm{g}$ total RNA in a final reaction volume of $20 \mu \mathrm{l}$ with MMLV reverse transcriptase (Promega Corp., Madison, WI, USA), $2.5 \mu \mathrm{M}$ oligo-dT primers, and $1 \mathrm{mM}$ dNTPs. The resulting cDNA was PCRamplified with Super-Therm DNA polymerase (SR Product, Kent, UK). The amount of RNA in each sample was normalized with GAPDH primers. PCR products were resolved on $2 \%$ agarose gels and visualized using Synergy Brands (SYBR) Green stain (Applied Biosystems, Carlsbad, CA, USA) with a LAS-3000 imaging system (Fujifilm Corp., Stamford, CT, USA).

\section{Real-time quantitative PCR analysis}

Real-time quantitative PCR analysis was performed using SYBR Green PCR master mix (Applied Biosystems, Carlsbad, CA, USA).

\section{Protein extraction}

Cells were washed with ice-cold phosphate-buffered saline (PBS) (Invitrogen Inc., Grand Island, NY, USA), resuspended in $100 \mu$ of ice-cold RIPA buffer $(25 \mathrm{mM}$ Tris- $\mathrm{HCl}$, $\mathrm{pH} 7.4,150 \mathrm{mM} \mathrm{KCl}, 5 \mathrm{mM}$ EDTA, $1 \% \mathrm{NP}-40,0.5 \%$ sodium deoxycholate, $0.1 \%$ SDS, $1 \mathrm{mM} \mathrm{Na} \mathrm{VO}_{4}, 5 \mathrm{mM}$ $\mathrm{NaF}$, and $1 \mathrm{mM}$ phenylmethylsulfonyl fluoride), and collected by scraping. Cells were ruptured by vortexing for $30 \mathrm{~s}$ two times at $30 \mathrm{~min}$ intervals while on ice, then centrifuged at $13,000 \mathrm{rpm}$ for $15 \mathrm{~min}$ at $4{ }^{\circ} \mathrm{C}$. Tissues, such as the aortas and the hearts, were homogenized in ice-cold RIPA buffer and centrifuged at $13,000 \mathrm{rpm}$ for $20 \mathrm{~min}$ at $4{ }^{\circ} \mathrm{C}$. Protein concentrations in the supernatants were quantified by the bicinchoninic acid method (Pierce Biotechnology Inc., Rockford, IL, USA) using bovine serum albumin as a standard.

\section{Western blot analysis}

Proteins were resolved on 8,10 , or $12 \%$ sodium dodecyl sulfate-polyacrylamide gels, then transferred to nitrocellulose membranes. Next, membranes were blocked in $1 \times$ TTBS 
$(10 \mathrm{mM}$ Tris- $\mathrm{HCl} \mathrm{pH} 7.5,150 \mathrm{mM} \mathrm{NaCl}$, and $0.05 \%$ Tween-20) containing 5\% skim milk for $30 \mathrm{~min}$ at room temperature. Membranes were probed with antibodies against phospho-AKT (pAKT), AKT, phospho-S6K (pS6K), S6K, PIK3CA, PIK3CB, phospho-ATM (pATM), ATM, phospho$\mathrm{Rb}$ (pRb), Rb, CD9, p53, phospho-p53 (p-p53), PARP 1/2, caspase 3 , p21, or p16 overnight at $4{ }^{\circ} \mathrm{C}$, after which secondary antibodies $(1: 3000)$ conjugated with horseradish peroxidase were applied to the membranes for $90 \mathrm{~min}$ at room temperature. After rinsing the membranes three times with $1 \times$ TTBS for $30 \mathrm{~min}$ each, antigen-antibody complex was detected using western blotting Luminol reagent (Santa Cruz Biotech Inc., Santa Cruz, CA, USA). Proteins were visualized with the Fujifilm LAS-3000 image system (Stamford, CT, USA). Antibodies against GAPDH or $\beta$-actin were used as a control for protein loading. The expression levels of proteins were quantified with the Image $\mathbf{J}$ program and normalized with the GAPDH or $\beta$-actin level.

\section{Preparation of human recombinant $C D 9$ adenovirus}

To produce human recombinant $C D 9$ adenovirus vector, full-length human $C D 9$ cDNA was amplified by PCR using Takara HS DNA polymerase (Shiga, Japan) with the following primers: forward primer, CCCCACTAGTCATGCC GGTCAAAGGAGGCA, and reverse primer, CCCCCTCG AGCTAGACCATCTCGCGGTTCCTGC. The PCR products were purified using a gel extraction kit (SolGent Corp. Ltd., Daejeon, Republic of Korea). The full-length $C D 9$ cDNA sequence was digested with XhoI and SpeI, then ligated into the same restriction enzyme sites of the pShuttle-IRES-hrGFP-2 vector, resulting in pShuttle/CD9 vector. Nucleotide sequences of a full-length $C D 9$ cDNA were confirmed by DNA sequencing (SolGent Corp. Ltd., Daejeon, Republic of Korea). Recombinant $C D 9$ adenoviral vectors were prepared by a double-recombination event in E. coli BJ5183 between the pAdEasy-1 vector and pShuttle/ $C D 9$ vector. Briefly, pShuttle/CD9 vectors were treated with PmeI and alkaline phosphatase (New England Biolabs Inc., Ipswich, MA, USA), then co-transformed into BJ5183 cells by electroporation with pAdEasy-1 vector, resulting in the vector $\mathrm{pAd} / C D 9$. BJ5183 colonies containing $\mathrm{pAd} / C D 9$ vectors were selected, and the presence of $\mathrm{pAd} / C D 9$ vectors was confirmed by PacI (New England Biolabs Inc., Ipswich, MA, USA) digestion. The recombinant $\mathrm{pAd} / C D 9$ vectors were linearized by $P a c I$ digestion and transfected into AD293 cells using Fugene HD transfection reagent (Roche Diagnostic Corp., Indianapolis, IN, USA) according to the manufacturer's protocol. Recombinant adenovirus was amplified in AD293 cells and purified using an adenovirus purification kit (Cell Biolabs Inc., San Diego, CA, USA). Virus titers were determined using the pAdEasy titer kit in AD293 cells.

\section{Transduction of recombinant CD9 adenovirus}

Young HUVECs $\left(\mathrm{PD}<28,1 \times 10^{5}\right.$ cells) were seeded in $60 \mathrm{~mm}$ culture dishes and incubated overnight. Cells were treated with 5,10 , and $15 \mathrm{MOI}$ of recombinant $C D 9$ adenovirus or negative control adenovirus for $24 \mathrm{~h}$. After discarding the media, cells were further incubated for the indicated times.

\section{Transfection of siRNA}

Senescent HUVECs (PD > 50, $1 \times 10^{5}$ cells) were transfected with $C D 9$ or negative control siRNA using Lipofectamine 2000 transfection reagent (Life Technologies Inc., Gaithersburg, MD, USA) according to the manufacturer's protocols.

Young cells $\left(1 \times 10^{5}\right)$ were seeded in $60 \mathrm{~mm}$ culture dishes and incubated overnight. siRNAs were transfected into cells using Lipofectamine 2000 transfection reagent (Invitrogen Life Technologies). After $24 \mathrm{~h}$ of incubation, cells were treated with 15 MOI of recombinant $C D 9$ adenovirus or negative control adenovirus for $24 \mathrm{~h}$. After discarding the media, cells were further incubated with growth media for the indicated times. The expression levels were then determined by RT-PCR or western blotting. SA $\beta$ G activity was measured at 4 days post transfection.

\section{Measurement of cell proliferation by live-cell time- lapse microscopy}

Senescent HUVECs $\left(1 \times 10^{5}\right.$ cells $)$ were transfected with $C D 9$ siRNA or negative control siRNA for $24 \mathrm{~h}$. The cells were then detached, seeded in 96-well plates, and incubated overnight. Young HUVECs $\left(1 \times 10^{5}\right.$ cells $)$ were transduced with recombinant $C D 9$ adenovirus or negative control adenovirus for $24 \mathrm{~h}$. The cells were then seeded in 96-well plates and incubated overnight. After discarding the media, cells were further incubated with growth media for 4 days, after which they were observed using a Leica ASMDW confocal microscope (Leica Microsystems GmbH, Wetzlar, Germany). Cell numbers were determined by counting at the indicated times.

\section{SABG staining for cells and tissues}

SA $\beta$ G activity of HUVECs, aorta en face, and frozen tissue sections was measured as previously described [25]. SA $\beta$ G activity was stained with X-gal or SPiDER- $\beta$ Gal (Dojindo Molecular Technologies, Inc., Kumamoto, Japan) according to the manufacturer's instruction.

\section{Flow cytometry}

Trypsinized cells were resuspended in $70 \%$ ethanol and incubated at $-20^{\circ} \mathrm{C}$ for at least $1 \mathrm{~h}$. After washing cells 
with PBS containing $2 \% \mathrm{FBS}$ and $0.01 \% \mathrm{CaCl}_{2}$, RNase $(1 \% \mathrm{w} / \mathrm{v})$ was added and incubated at $37^{\circ} \mathrm{C}$ for $30 \mathrm{~min}$. Cells were then centrifuged, resuspended in PBS containing propidium iodide $(50 \mu \mathrm{g} / \mathrm{ml})$, and incubated for $20 \mathrm{~min}$. Next, cell cycle distributions were analyzed by measuring the intracellular propidium iodide fluorescence intensity of each population of 10,000 cells using a Becton-Dickinson FACS Canto II flow cytometer (Becton-Dickinson, San Jose, CA, USA).

\section{Rhodamine-conjugated phalloidin and 4',6- diamidino-2-phenylindole (DAPI) staining}

Cells seeded on glass coverslips were rinsed three times with PBS, then fixed with $3.7 \%(\mathrm{v} / \mathrm{v})$ paraformaldehyde in PBS for 10 min. After treatment with $0.2 \%$ Triton $\mathrm{X}-100$ in PBS for $5 \mathrm{~min}$, actin cytoskeletons in the cells were stained with rhodamine-conjugated phalloidin (Sigma-Aldrich, Inc., St. Louis, MO, USA) and nucleus with $2 \mu \mathrm{g} / \mathrm{ml}$ DAPI in PBS. The glass coverslips were then washed with PBS, briefly dried, and mounted. Fluorescent images were acquired using a fluorescence microscope.

\section{Endothelial cell tube formation assay}

Ninety-six well plates were coated with $65 \mu$ of Matrigel (Becton Dickinson, Bedford, MA). Young HUVECs $(2.5 \times$ $10^{4}$ cells/well) transduced with recombinant $C D 9$ adenovirus or negative control adenovirus were plated in duplicate and incubated at $37^{\circ} \mathrm{C}$ for $4 \mathrm{~h}$. Senescent HUVECs $\left(2.5 \times 10^{4}\right.$ cells/well $)$ transfected with $C D 9$ or negative control siRNA were plated in duplicate and incubated at $37^{\circ} \mathrm{C}$ for $4 \mathrm{~h}$. Tube formation was observed with a light microscope.

\section{Cell and tissue immunohistochemical staining}

Cells were seeded on glass coverslips and incubated for $24 \mathrm{~h}$. Next, cells were rinsed three times with PBS, after which they were fixed with $3.7 \%$ (v/v) paraformaldehyde in PBS for $10 \mathrm{~min}$. Cells were then rinsed three times with PBS, blocked in 3\% goat serum (Invitrogen Corp) for 45 min, and then stained with a CD9 antibody or a Ki67 antibody at $37^{\circ} \mathrm{C}$ overnight. Cells were subsequently incubated with Alexa Fluor 546-conjugated goat anti-rabbit IgG (dilution 1:10,000; Molecular Probes, Eugene, OR) for $2 \mathrm{~h}$, after which DAPI staining was performed and cells were observed with a confocal microscope.

Paraffin-embedded tissue blocks were sectioned at $5 \mu \mathrm{m}$, then attached to silane-coated slides. Vascular tissues of the spleens and testes from human subjects and aortic sinus tissues of $\mathrm{ApoE}^{-/-}$or $\mathrm{Ldlr}^{-/-}$mice were immunohistochemically stained with a CD9 antibody using a Dako
Envision Kit (ChemMate ${ }^{\mathrm{TM}}$, DAKO EnVision ${ }^{\mathrm{TM}}$, Denmark) according to the manufacturer's instructions. Mayer's hematoxylin was used for counterstaining.

CD9 immunoreactivity in arteries of human tissues was assessed by measuring the intensity of cytoplasmic staining and the extent of staining in endothelial cells and smooth muscle cells by two pathologists. The intensity of cytoplasmic staining was scored as follows: $0+$ (absent), 1+ (weakly positive), $2+$ (moderately positive), and $3+$ (strongly positive). The extent of staining was scored as follows: $0+(0 \%)$, $1+(1-25 \%), 2+(26-50 \%), 3+(51-75 \%)$, and $4+(>75 \%)$. The final score was determined by multiplying the intensity score and the extent score (range, 0-12). For statistical analysis, the CD9 immunoreactivity was then defined as negative (score 0) and positive (score 1-12).

Frozen tissue sections of atherosclerotic lesions were incubated with antibodies against PECAM, an endothelial cell marker, p53, p16, and F4/80, a macrophage marker, overnight at $4{ }^{\circ} \mathrm{C}$ and then stained with fluorophore-conjugated secondary antibodies, after which DAPI staining was performed and cells were observed with a confocal microscope. The expression levels of proteins in tissue sections were quantified with the Image $\mathrm{J}$ program.

\section{Assessment of BrdU incorporation}

Intracellular BrdU incorporation was measured using a BrdU flow kit. Young cells were transduced with recombinant $C D 9$ adenovirus and senescent cells were transfected with $C D 9$ siRNA, after which they were incubated for 5 days and treated with BrdU for 1 day. The median fluorescence intensity of BrdU in 10,000 cells was measured using a Becton-Dickinson FACS Canto II flow cytometer (BD Bioscience) and relative ratio of BrdU fluorescence intensities of siRNA-transfected or adenovirus-transduced cells to those of control cells were calculated.

\section{Preparation of low-density lipoprotein (LDL) and oxidized LDL (oxLDL)}

LDL $(1.019<\mathrm{d}<1.063)$ was purified from healthy human plasma obtained from the Blood Bank of Yeungnam University Medical Center, Daegu, Republic of Korea. Samples were centrifuged for $24 \mathrm{~h}$ at $10^{\circ} \mathrm{C}$ at $100,000 \times g$ using a Himac CP-90a (Hitachi, Tokyo, Japan) as detailed in our previous report [26] and in accordance with standard protocols [27]. After ultracentrifugation, the isolated LDL was characterized to determine the lipid and protein component as previously described [26]. To prepare oxLDL, LDL ( $1.019 \mathrm{mg}$ of protein) was incubated with $10 \mu \mathrm{M} \mathrm{CuSO} 4$ (final concentration) for up to $4 \mathrm{~h}$. During incubation, the formation of conjugated dienes was monitored at $24.5^{\circ} \mathrm{C}$ using a DU800 spectrophotometer $(234 \mathrm{~nm})$ equipped with 
a MultiTemp III thermocirculator (Amersham, Uppsala, Sweden), as previously described [26]. To verify the spectroscopic data, the oxidized LDL samples were subjected to electrophoresis on $0.5 \%$ agarose gels for comparison of the relative electromobility [28]. The oxLDL was then filtered $(0.2 \mu \mathrm{m})$ and analyzed using a thiobarbituric acid reacting substances (TBARS) assay to determine the extent of oxidation, as previously described [29]. The extent of LDL modification was expressed as nanomoles of malondialdehyde per milligram of LDL protein (TBARS). oxLDL with TBARS values between 100 and $120 \mathrm{nmol} / \mathrm{mg}$ LDL protein was used in this study.

\section{Treatment of cells with oxLDL and CD9 antibody}

The mouse endothelial cell line, MS-1, and the mouse macrophage cell line, Raw264.7, were treated with $50 \mu \mathrm{g} / \mathrm{ml}$ of $\mathrm{LDL}$ or oxLDL, and $10 \mu \mathrm{g} / \mathrm{ml}$ of rat $\mathrm{IgG}(\mathrm{rgG})$ or CD9 antibody ( $\alpha \mathrm{rCD} 9)$ for 3 days. Lipid accumulation was observed by Oil-red $\mathrm{O}$ staining and cellular senescence by $\mathrm{SA} \beta \mathrm{G}$ activity staining.

\section{Intraventricular injection of rhodamine-conjugated CD9 antibody in $\mathrm{ApoE}^{-/-}$mice}

$A p o E^{-/-}$male mice (19 weeks old) were fed a high-fat diet for 21 weeks and then rhodamine-conjugated $\alpha \mathrm{rCD} 9$ or $\mathrm{rgG}$ and FITC-conjugated CRKRLDRNC peptide were injected into the left ventricle. Mice were perfused with ice-cold PBS and fixed with $3.7 \%$ paraformaldehyde in PBS. After which, the aortic tissues and heart were harvested. The expression levels of CD9 were analyzed in atherosclerotic lesions and normal regions of aortas with confocal microscopy.

\section{Atherosclerotic lesion analysis in aorta and aortic sinus}

Mice were sacrificed and perfused with ice-cold PBS, after which the aortic tissues and hearts were harvested. For en face staining, aortas were opened longitudinally and subjected to SA $\beta G$ activity and Oil-red $O$ staining [30]. The aortic sinus tissues were embedded in OCT compound, after which serial sections from the opening of the coronary artery to the end of aortic valve were collected at $20 \mu \mathrm{m} / \mathrm{section}$. Tissue sections were subsequently subjected to SA $\beta \mathrm{G}$ activity staining, CD9 immunohistochemical staining, and Oil-red $\mathrm{O}$ staining. The extents of atherosclerotic lesions in the aorta and aortic sinus were analyzed using the Image $\mathbf{J}$ program.

\section{Statistical analysis}

In in vitro experiments, we conducted at least three independent experiments and the results were presented as the means \pm SD. In in vivo experiments, the results were presented as the means \pm SE. $p$ values for determining statistical significance were calculated using an unpaired two-tailed Student's $t$ test, and one-way Anova or two-way Anova followed by Tukey's post hoc test in Graphpad Prism 7.0.

\section{Results}

\section{Knockdown of CD9 in senescent HUVECs rescues cellular senescence}

To examine the roles of CD9 in endothelial cell senescence, we measured the effects of $C D 9$ knockdown in senescent HUVECs (PD > 50). Knockdown of CD9 in senescent cells with siRNA reduced the p53 and p21 levels, representative senescence markers, and the pAKT and pS6K levels (Fig. 1a), decreased SA $\beta$ G staining (Fig. 1b, c), and caused morphological changes similar to those observed in young cells (Supplementary Fig. S1A). CD9 downregulation increased cell proliferation (Fig. 1d), BrdU incorporation (Fig. 1e), and Ki67 immunoreactivity (Supplementary Fig. $\mathrm{S} 1 \mathrm{~B})$, which are all well-known cell proliferation markers [31]. CD9 knockdown decreased the G0/G1 cell population and increased the $S$ and G2/M cell population, suggesting a release of G1 arrest (Fig. 1f, Supplementary Fig. S1C, and Supplementary Table 3), which is a typical phenotype in cellular senescence [32]. While senescent cells secrete many pro-inflammatory cytokines [4], CD9 knockdown decreased the levels of $I L-6$ and $I L-1 \beta$ (Fig. $1 \mathrm{~g}$ ). HUVECs form tube structures in vitro following exposure to angiogenic factors [33], which decreases in senescent cells [34]. CD9 downregulation recovered tube formation that was decreased in senescent cells (Fig. 1h). Taken together, these findings suggest that CD9 knockdown in senescent cells significantly reverses cellular senescence.

\section{Ectopic expression of CD9 in young HUVECs induces cellular senescence}

We next tested whether CD9 overexpression in young cells accelerates cellular senescence using recombinant human CD9 adenovirus. CD9 upregulation decreased the levels of $\mathrm{pRb}$ and increased the levels of p53, p-p53, p21, IL-6, and $I L-1 \beta$ (Fig. $2 \mathrm{a}, \mathrm{b}$ ). Young cells transduced with $C D 9$ adenovirus were enlarged and flattened (Supplementary Fig. S2A, B). Moreover, CD9 upregulation increased SA $\beta$ G staining (Fig. 2c), but decreased BrdU incorporation (Fig. 2d), Ki67 immunoreactivity (Supplementary Fig. $\mathrm{S} 2 \mathrm{C}$ ), the proportion of cells in the $\mathrm{S}$ phase (Fig. 2e, Supplementary Fig. S2D, and Supplementary Table 4), and endothelial tube formation (Fig. 2f). We further examined the effects of CD9 upregulation on cell proliferation for up 

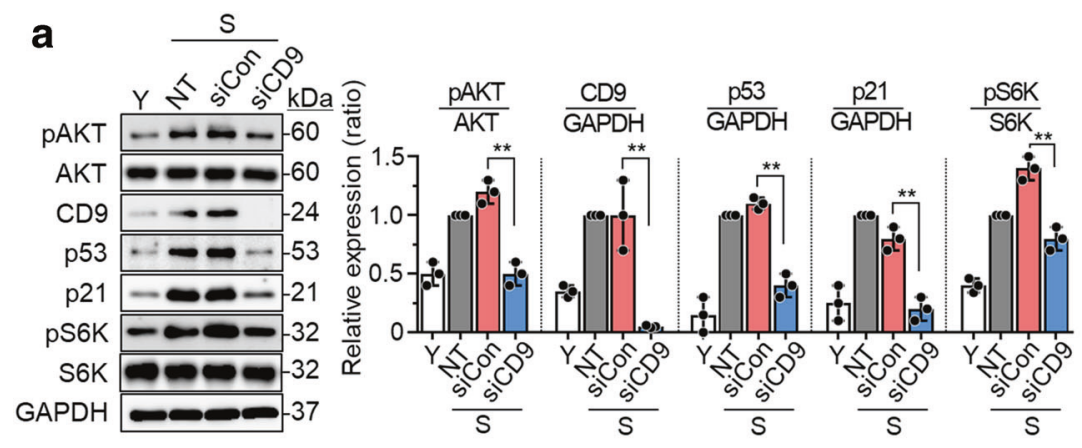

b
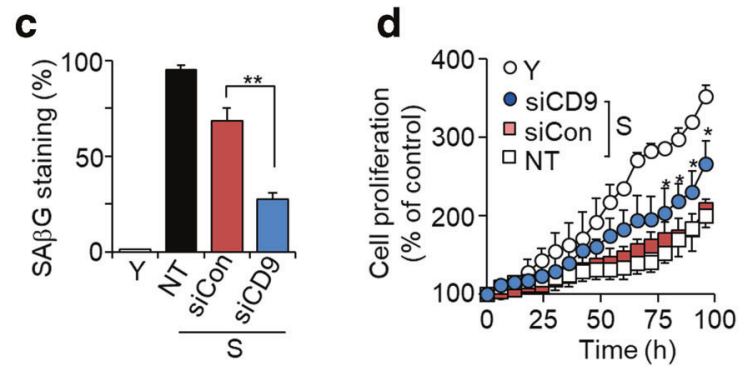

e
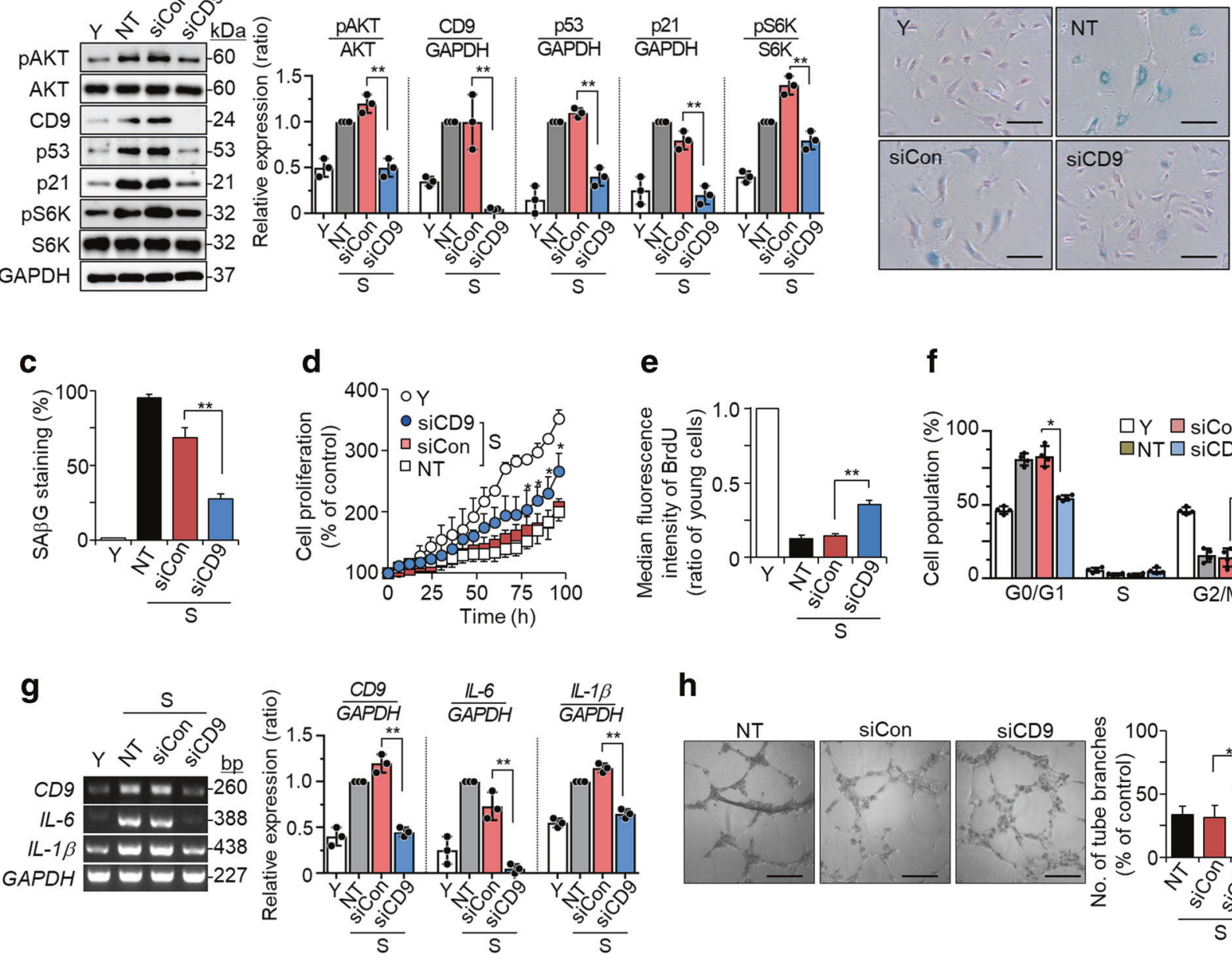

$\mathbf{f}$

h

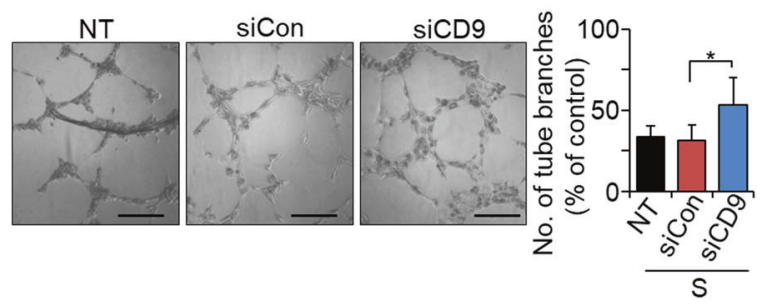

Fig. 1 Knockdown of CD9 in senescent cells rescues cellular senescence. Senescent HUVECs $(\mathrm{PD}>50)$ were transfected with $C D 9$ or negative control siRNA and then incubated for 6 days at $37^{\circ} \mathrm{C}$. a The levels of pAKT, AKT, CD9, p53, p21, pS6K, and S6K proteins by western blotting and their relative levels. b SA $\beta G$ staining (blue). Scale bar: $20 \mu \mathrm{m}$. c The percentages of SA $\beta$ G positive cells. d Cell proliferation measured by live-cell time-lapse microscopy and cell counting. e BrdU incorporation measured by

flow cytometry. f Cell cycle analysis measured by flow cytometry. g The expression levels of $I L-6$ and $I L-1 \beta$ mRNAs by RTPCR and their relative levels. $\mathbf{h}$ Tube formation in HUVECs. Scale bar: $200 \mu \mathrm{m}$. Representative data are shown and the values are the means \pm SD of three independent experiments. Y young cells, $S$ senescent cells, NT not treated, siCon negative control siRNA, siCD9 CD9 siRNA; ${ }^{*} p<0.05$ and ${ }^{* *} p<0.01$.

to 36 days. PD levels gradually decreased in response to CD9 upregulation, and significant differences were observed after 24 days (Fig. $2 \mathrm{~g}$ ). In addition, the levels of p53, p-p53, and p21 proteins increased (Fig. 2h). Interestingly, CD9 upregulation did not alter the pATM level (Fig. 2a), which is known to be increased by DNA damage response (DDR) during cellular senescence [35, 36]. To confirm whether DDR occurs during CD9-mediated cellular senescence, we measured the $\gamma \mathrm{H} 2 \mathrm{AX}$ level (a phosphorylated form of the histone variant $\mathrm{H} 2 \mathrm{AX}$ ) because DDR is associated with the appearance of foci that stain positive for $\gamma \mathrm{H} 2 \mathrm{AX}$ in the nucleus [37]. $\gamma \mathrm{H} 2 \mathrm{AX}$ foci were not increased in $C D 9$ adenovirus-transduced cells (Supplementary Fig. S2E). Since apoptosis might contribute to the reduction of cell proliferation in $C D 9$ adenovirus cells, we measured the cleavage of PARP $1 / 2$ and caspase 3, which are well-known apoptotic indicators [38]. No cleavage of PARP $1 / 2$ and caspase 3 was observed (Supplementary Fig. S2F). These results suggest that ectopic expression of $\mathrm{CD} 9$ in young cells accelerates cellular senescence.

\section{CD9 regulates cellular senescence through a PI3K- AKT-mTOR-p53 pathway}

We investigated which signal transduction pathway contributes to CD9-mediated cellular senescence. Since two tumor suppressor pathways, $\mathrm{p} 53 / \mathrm{p} 21$ and $\mathrm{Rb} / \mathrm{p} 16$, are known to regulate cellular senescence [39], cells were 


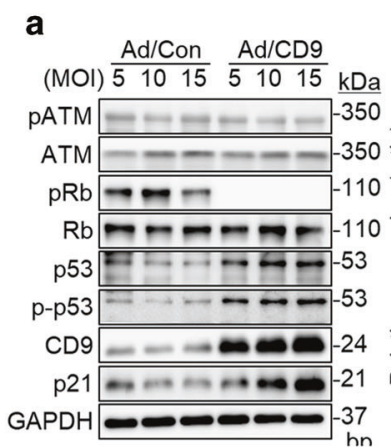

C

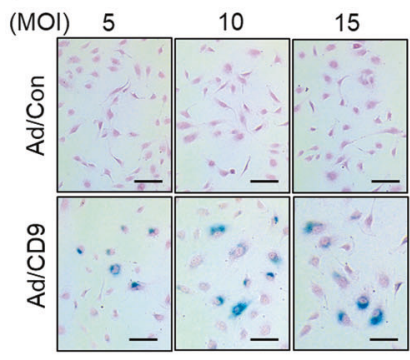

e

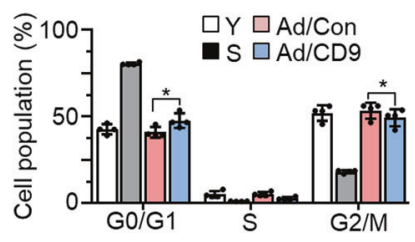

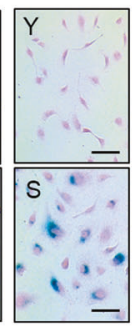

f
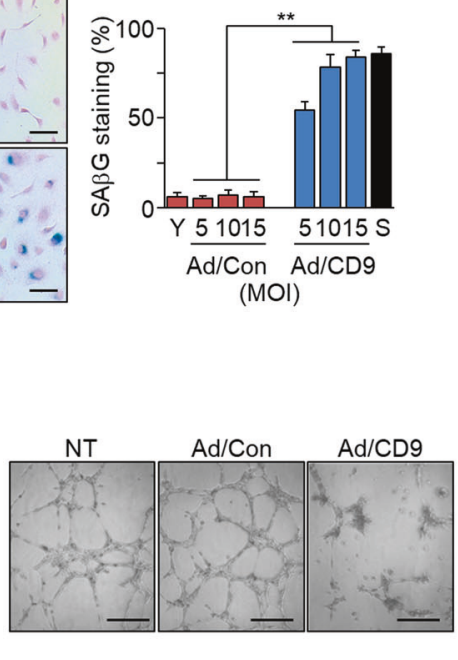

d
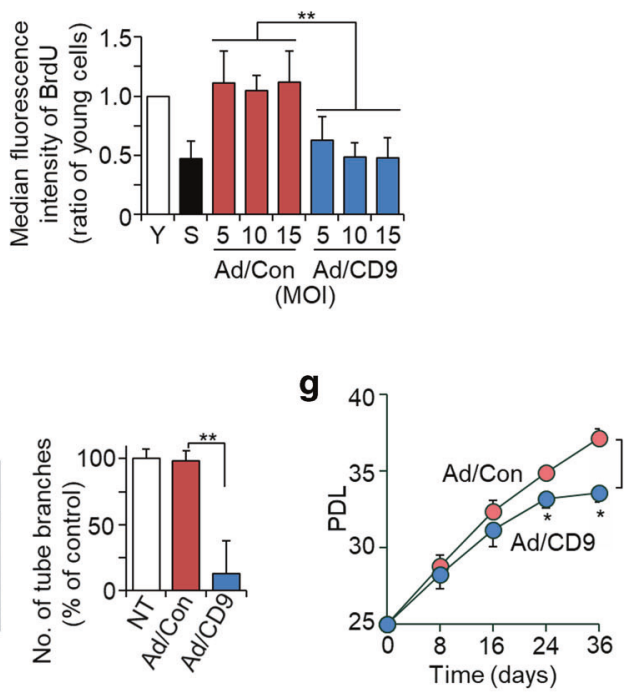

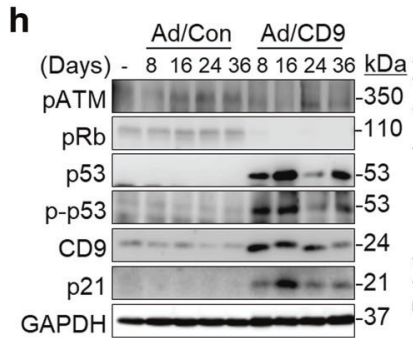

Fig. 2 Ectopic expression of CD9 in young cells accelerates cellular senescence. a-f Young HUVECs $(\mathrm{PD}<28)$ were transduced with recombinant human $C D 9$ or negative control adenovirus and incubated for 6 days at $37^{\circ} \mathrm{C}$. a The levels of pATM, pRb, p53, p-p53, and p21 proteins by western blotting and their relative levels. b The levels of $I L-6$ and $I L-1 \beta$ mRNAs by RT-PCR and their relative levels. c SA $\beta$ G staining and the percentages of SA $\beta G$ positive cells. Scale bar: $20 \mu \mathrm{m}$. d BrdU incorporation analyzed by flow cytometry. e Cell cycle analysis by flow cytometry (each, $n=4$ ). f Endothelial tube formation. Scale bar: $200 \mu \mathrm{m}$. g, h Young cells were transduced with 5 MOI of

transfected with $p 53$ or p16 siRNA (Fig. 3a and Supplementary Fig. S3A) prior to transduction with $C D 9$ adenovirus. The increase in $\mathrm{SA} \beta \mathrm{G}$ staining induced by $\mathrm{CD} 9$ upregulation was repressed by 533 knockdown, but not by p16 knockdown (Fig. 3b and Supplementary Fig. S3B), b

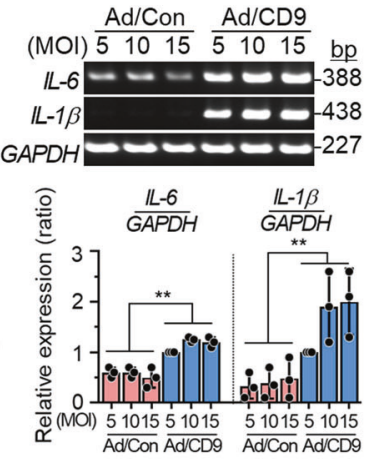

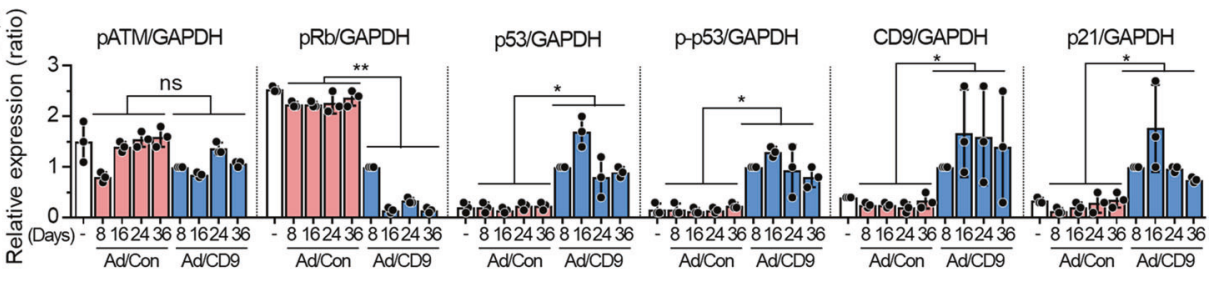

recombinant human $C D 9$ or negative control adenovirus and incubated for the indicated times. $\mathrm{g}$ Cell proliferation analyzed by measuring PDL. h The levels of pATM, pRb, p53, p-p53, and p21 proteins by western blotting and their relative levels. Representative data are shown and the values are the means \pm SD of three independent experiments. Y young cells, S senescent cells, NT not treated, Ad/Con negative control recombinant adenovirus, Ad/CD9 recombinant human $C D 9$ adenovirus, MOI multiplicity of infection, PDL population doubling level, ns not significant; $* p<0.05$ and $* * p<0.01$.

suggesting that a 553 pathway might regulate CD9-induced cellular senescence. To determine the contribution of activated ATM signaling to CD9-induced senescence, cells were transfected with ATM siRNA and the CD9-induced cellular senescence was measured. ATM knockdown did not 


\section{a}

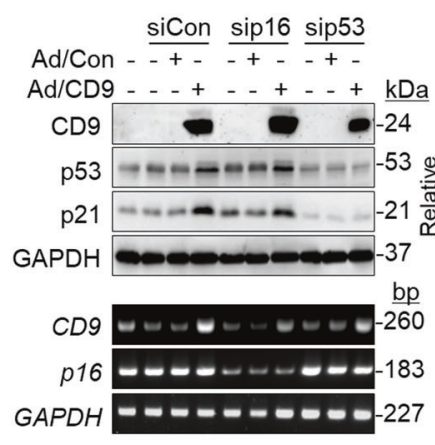

b

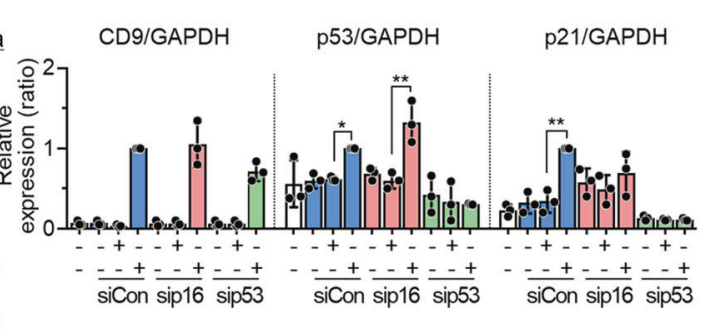

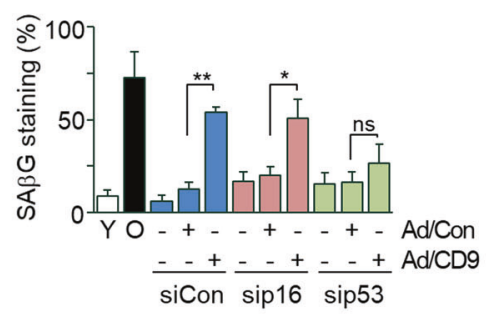

\section{.}

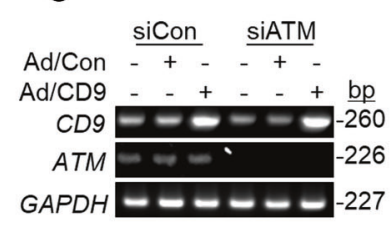

e
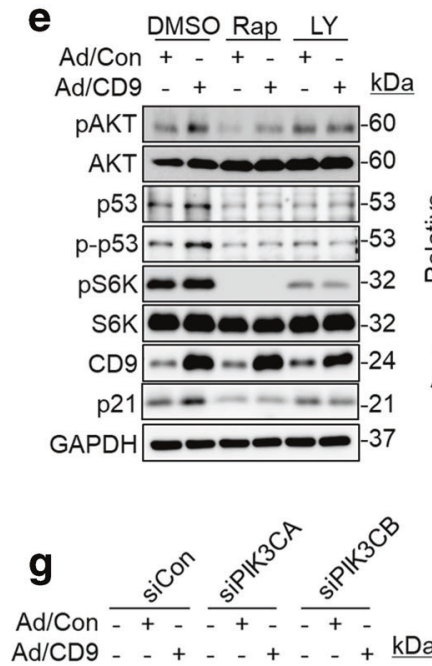

$\mathrm{Ad} / \mathrm{CD} 9$

$\mathrm{pRb} \longrightarrow----110$

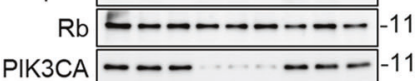

РІКЗСВ -

рАКT $--(-1-\cdots-60$

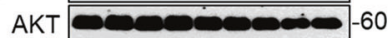

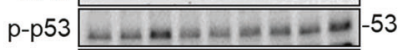

$\mathrm { p } 5 3 \longdiv { \mathrm { W } = \mathrm { n } } - 5 3$

p21 $=-\pi=n-21$

CD9 \#............ -24

pS6K $-\cdots-32$

S6K Seren 32

GAPDH

- 37

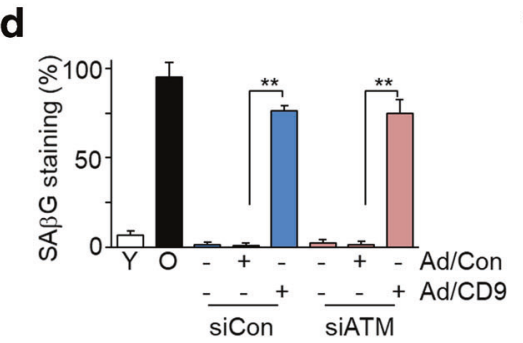

f
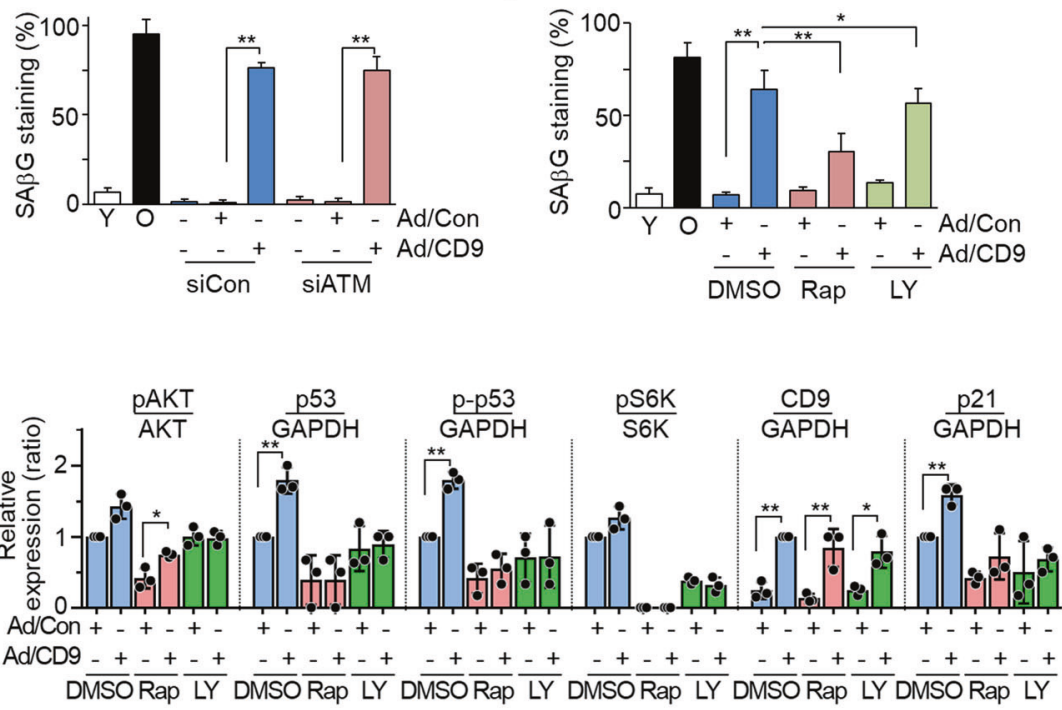

h
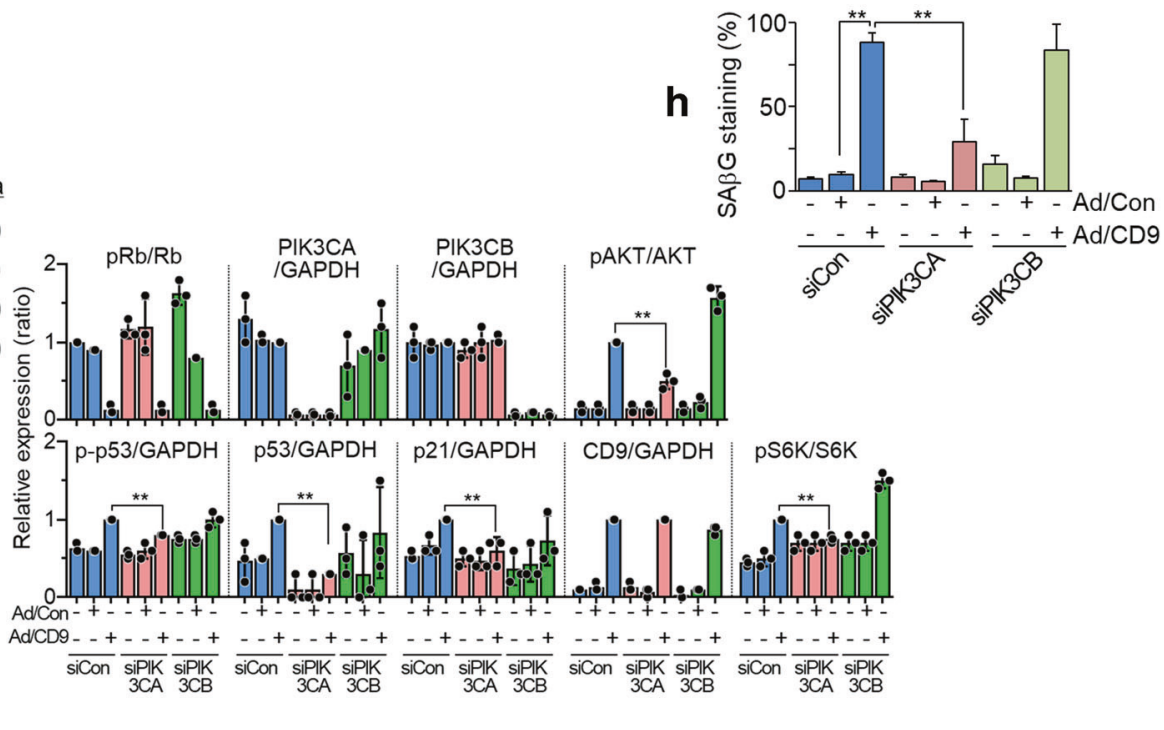

affect SA $\beta$ G staining (Fig. 3c, $d$ and Supplementary Fig. S3C, D), suggesting that DDR might not contribute to CD9induced senescence. Hyperactivation of the PI3K/AKT pathway is crucial to p53-mediated senescence [40], and
CD9 modulates the PI3K/AKT pathway in VSMCs [21]. Mammalian target of rapamycin (mTOR) is a downstream molecule of the PI3K/AKT pathway related to translation and cell proliferation [41]. Therefore, we tested whether the 
Fig. 3 CD9 regulates cellular senescence through a PI3K-AKTmTOR-p53 dependent pathway. Young HUVECs $(\mathrm{PD}<28)$ were transfected with $p 53, p 16, A T M, P I K 3 C A, P I K 3 C B$, or control siRNA and incubated for $24 \mathrm{~h}$. Young cells were treated with $20 \mu \mathrm{M}$ LY294002 or $10 \mathrm{nM}$ rapamycin for $4 \mathrm{~h}$, after which the cells were transduced with recombinant human $C D 9$ or negative control adenovirus. After 6 days, senescence phenotypes were measured. a The levels of $\mathrm{p} 53, \mathrm{p} 21$, and $\mathrm{p} 16$ proteins and mRNAs in $p 53, \mathrm{p} 16$, or control siRNA cells, and relative expression levels of proteins. b The percentages of $\mathrm{SA} \beta \mathrm{G}$ positive cells in $p 53, p 16$, or control siRNA cells. $\mathbf{c}$ The levels of $C D 9$ and $A T M$ mRNAs in $A T M$ or control siRNA cells. d The percentages of SA $\beta \mathrm{G}$ positive in ATM or control siRNA cells. e The levels of pAKT, p53, p-p53, pS6K, and p21 proteins, and their relative levels in cells treated with rapamycin or LY294002. f The percentages of $S A \beta G$ positive cells in rapamycin or LY294002-treated cells. g The levels of pRb, PIK3CA, PIK3CB, pAKT, p-p53, p53, p21, and pS6K proteins, and their relative levels in PIK3CA, PIK3CB, or control siRNA cells. $\mathbf{h}$ The percentages of $\mathrm{SA} \beta \mathrm{G}$ positive cells in PIK3CA, PIK3CB, or control siRNA cells. Representative data are shown and values are the means \pm SD of three independent experiments. siCon negative control siRNA, sip53 p53 siRNA, sip16 p16 siRNA, siATM ATM siRNA, DMSO dimethyl sulfoxide, LY LY294002, Rap rapamycin, siPIK3CA PIK3CA siRNA, siPIK3CB $P I K 3 C B$ siRNA, Ad/Con recombinant negative control adenovirus, $\mathrm{Ad} / \mathrm{CD} 9$ recombinant human $C D 9$ adenovirus, ns not significant; ${ }^{*} p<$ 0.05 and $* * p<0.01$.

PI3K/AKT-mTOR pathway plays a role in CD9-induced senescence. Pretreatment with LY294002, a specific inhibitor of PI3K [42], or rapamycin, an inhibitor of mTOR [43], reduced the levels of p53 and p21 (Fig. 3e) and SA $\beta G$ staining induced by CD9 overexpression (Fig. 3f and Supplementary Fig. S3E). We next tested whether PIK3CA $110 \alpha$ or PIK3CB $110 \beta$, two PI3K catalytic subunits [44], plays a role in CD9-induced senescence. Knockdown of PIK3CA, but not that of PIK3CB, significantly decreased the levels of pAKT, p53, p-p53, pS6K, and p21 proteins, as well as SA $\beta$ G staining (Fig. 3g, h and Supplementary Fig. $\mathrm{S} 3 \mathrm{~F}$ ), suggesting that PIK3CA might be involved in CD9induced cellular senescence. These results indicate that the PI3K-AKT-mTOR-p53 pathway might regulate CD9mediated cellular senescence (Supplementary Fig. S3G).

\section{CD9 levels increase in vascular tissues with age and in atherosclerotic lesions of humans and mice}

Vascular cell senescence contributes to age-related vascular diseases [7]. Since CD9 levels increase in senescent endothelial cells [20], we examined its expression in human or rat vascular tissues with increasing age and in atherosclerotic lesions of humans and mice. The CD9 immunoreactivity in human arteries increased gradually with age, peaked at 61-70 years, then slightly decreased at 81-90 years (Fig. 4a). The CD9 levels were upregulated in the aorta and the heart of old rats (24-months old) relative to those of young rats (6-months old) (Fig. 4b). CD9 immunoreactivity increased in atherosclerotic lesions of human carotid arteries (Fig. 4c).
Consistently, CD9 immunostaining and SA $\beta$ G staining were enhanced in atherosclerotic lesions of aortic sinus sections in $A p o E^{-/-}$mice with age (Fig. 4d) and in $\mathrm{Ldlr}^{-/}$mice (Supplementary Fig. S4A). CD9 expression in frozen tissue sections of atherosclerotic lesions of $A p o E^{-/}$mice was colocalized with the SA $\beta \mathrm{G}$ activity, which was confirmed fluorescence based SA $\beta$ G staining (Fig. 4e). In addition, the level of CD9 protein was upregulated in endothelial cells as well as macrophages in atherosclerotic lesions of $A p o E^{-/-}$ mice (Fig. 4f). CD9 upregulation was also confirmed in replicative senescence and adriamycin-induced premature cellular senescence (Supplementary Fig. S4B, C). The level of CD9 was upregulated in endothelial cells of atherosclerotic lesions compared with those of normal regions (Supplementary Fig. S4D, E). CD9 expression was colocalized with the IL-4 receptor (IL4R) in endothelial cells, which was reported to be upregulated in atherosclerotic lesions and confirmed with the IL4R binding peptide, CRKRLDRNC [45]. These findings suggest that CD9 might be involved in endothelial cell senescence and contribute to the formation of atherosclerotic lesion.

\section{A rat monoclonal antibody against mouse CD9 and genetic ablation of CD9 alleviated atherosclerotic plaque formation in $\mathrm{ApoE}^{-/-}$mice}

CD9 knockdown in senescent cells significantly rescues cellular senescence. Therefore, we tested whether a blocking antibody against CD9 inhibits the formation of atherosclerotic lesions in $A p o E^{-/-}$mice that develop atherosclerosis due to impaired clearing of plasma lipoproteins [46]. We examined the effects of a rat monoclonal antibody against mouse CD9 ( $\alpha \mathrm{rCD} 9$ ) and a rat $\mathrm{IgG}$ $(\mathrm{rIgG})$ on cellular senescence using the mouse endothelial cell line (MS-1) and macrophage cell line (Raw264.7). We also investigated their effects on the formation of atherosclerotic lesions in $A p o E^{-/-}$mice. $\alpha \mathrm{rCD} 9$ inhibited SA $\beta \mathrm{G}$ staining (Supplementary Fig. S5A) and lipid uptake induced by oxLDL (Supplementary Fig. S5B) in MS-1 and Raw264.7 cells. We intraperitoneally injected $100 \mu \mathrm{g}$ of arCD9 or rIgG to mice every 3.5 days for 15 weeks while feeding them a high-fat diet. Body weights were lower in the $\alpha \mathrm{rCD} 9$ group than in the $\mathrm{rgG}$ group (Supplementary Fig. S5C), whereas total food intakes did not differ significantly between groups (Supplementary Fig. S5D). The levels of total cholesterol and LDL cholesterol were lower in the $\alpha \mathrm{rCD} 9$ group than the $\mathrm{IgG}$ group (Supplementary Fig. S5E). $\alpha \mathrm{CCD} 9$ decreased atherosclerotic plaque lesions and SA $\beta$ G staining in aortic arches (Fig. 5a and Supplementary Fig. S5F), SA $\beta$ G staining in aorta en face (Fig. 5b), and frozen tissue sections of atheroma obtained from aorta en face (Fig. 5 c). $\alpha \mathrm{rCD} 9$ reduced atherosclerotic plaque lesions, SA $\beta G$ staining, and CD9 expression in the aortic 
Fig. 4 Upregulation of CD9 in human and rat arterial tissues with age and in atherosclerotic lesions of human carotid arteries and aortic sinuses in ApoE $^{-/-}$mice. a CD9 immunostaining (brown) and CD9 immunoreactivity in human arterial tissues with age in each group (each, $n=20$ ). Scale bar: $200 \mu \mathrm{m}$. b Levels of CD9 protein measured by western blotting in the aortas and the hearts of 6- and 24months old rats.

c Representative CD9 immunostaining (brown) in atherosclerotic lesions in human carotid arteries $(n=6)$. Scale bar: $500 \mu \mathrm{m}$. d Staining for Oilred O (red), CD9

immunoreactivity (brown), and $\mathrm{SA} \beta \mathrm{G}$ (blue) in aortic sinus sections from $A p o E^{-/-}$mice with age (each, $n=5$ ). Scale bar: $200 \mu \mathrm{m}$.

e Immunofluorescence staining and colocalization of CD9 with SPiDER- $\beta$ Gal, a fluorescence marker of SA $\beta \mathrm{G}$ in frozen tissue sections of atherosclerotic lesions of $\operatorname{ApoE}^{-/-}$mice $(n=5)$. Scale bar: $30 \mu \mathrm{m}$.

f Immunofluorescence staining and colocalization of CD9 with PECAM, an endothelial cell marker, and F4/80, a macrophage marker in frozen tissue sections of atherosclerotic lesions of $\operatorname{ApoE}^{-/-}$mice $(n=5)$. Scale bar: $5 \mu \mathrm{m}$. $C D 9^{-/-} C D 9$ deficient mice, L lumen of artery, $\mathrm{AP}$ atherosclerotic plaque, $A p o E^{-/-}$apolipoprotein E deficient mice, WT C57BL/6 mice, $\mathrm{NC}$ without $\mathrm{CD} 9$ primary antibody; ${ }^{*} p<0.05$ and $* * p<0.01$.

\section{a}

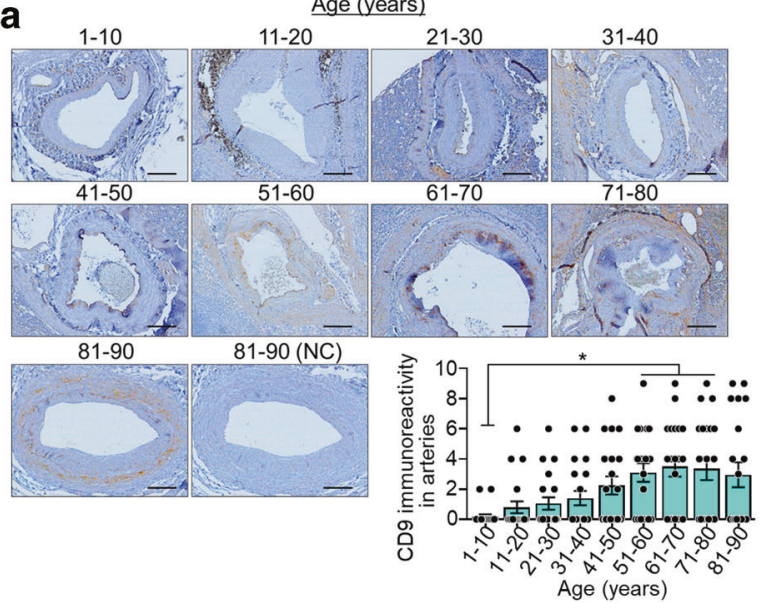

b

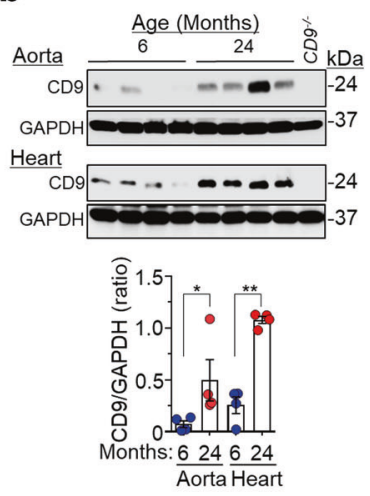

C

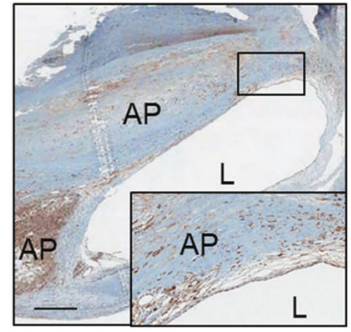

e

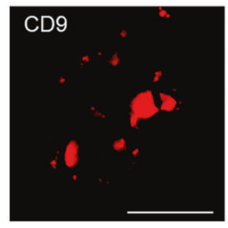

f
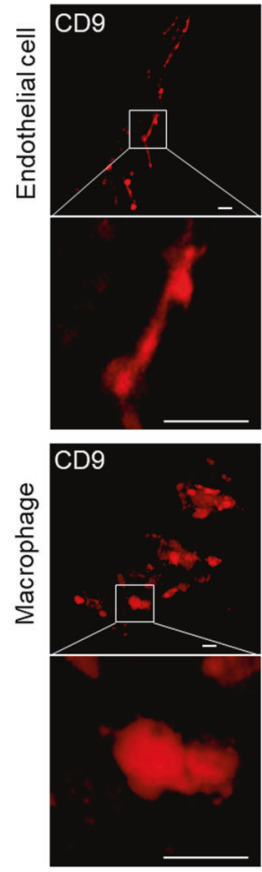
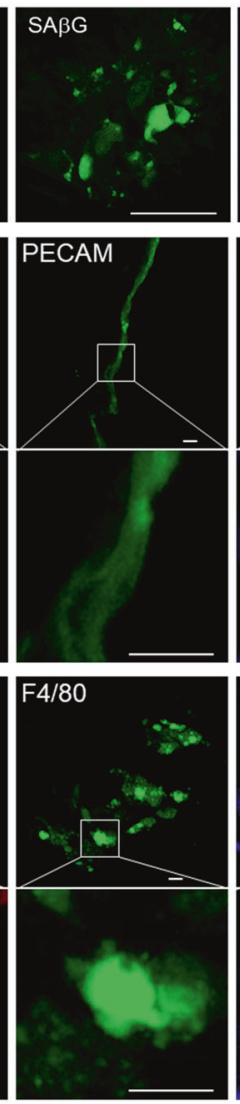

d
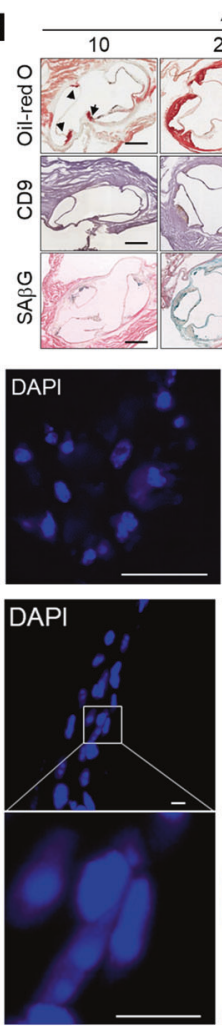

DAPI

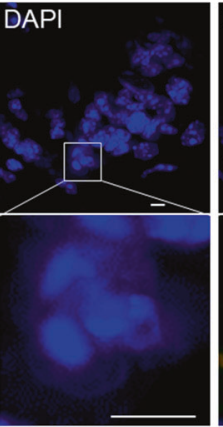

$\mathrm{ApoE}^{-1-}$ (weeks)

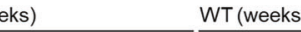



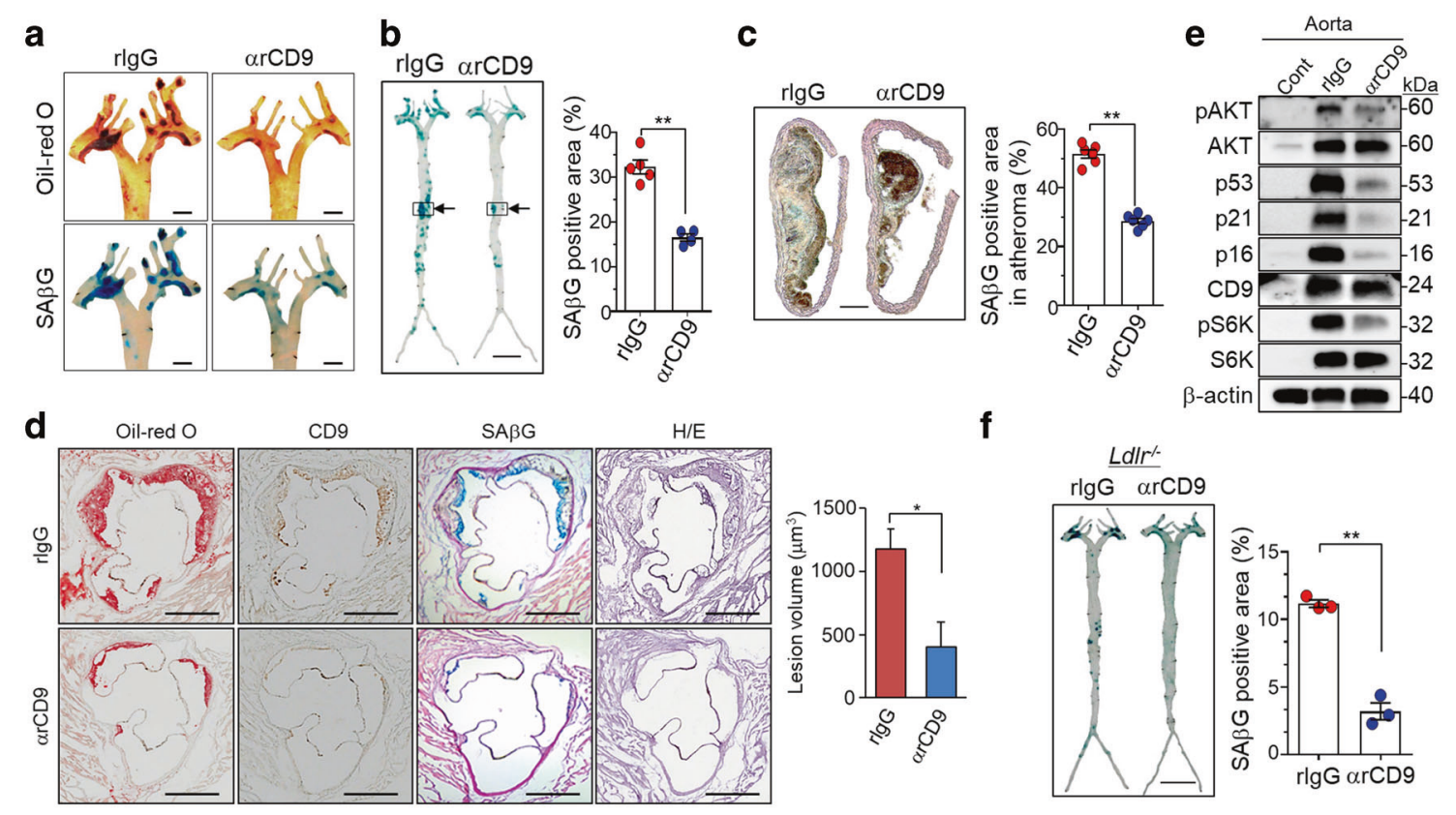

f
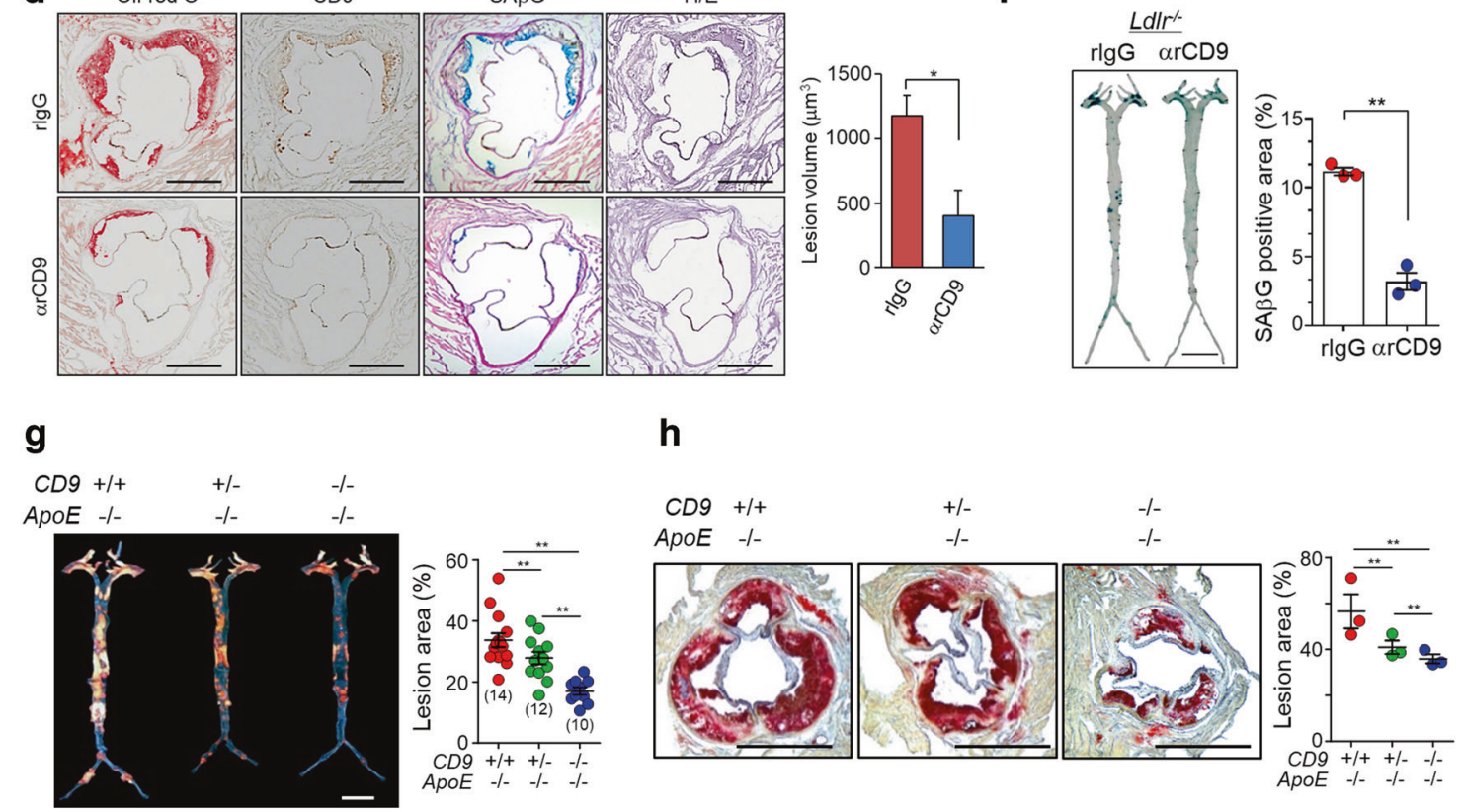

h
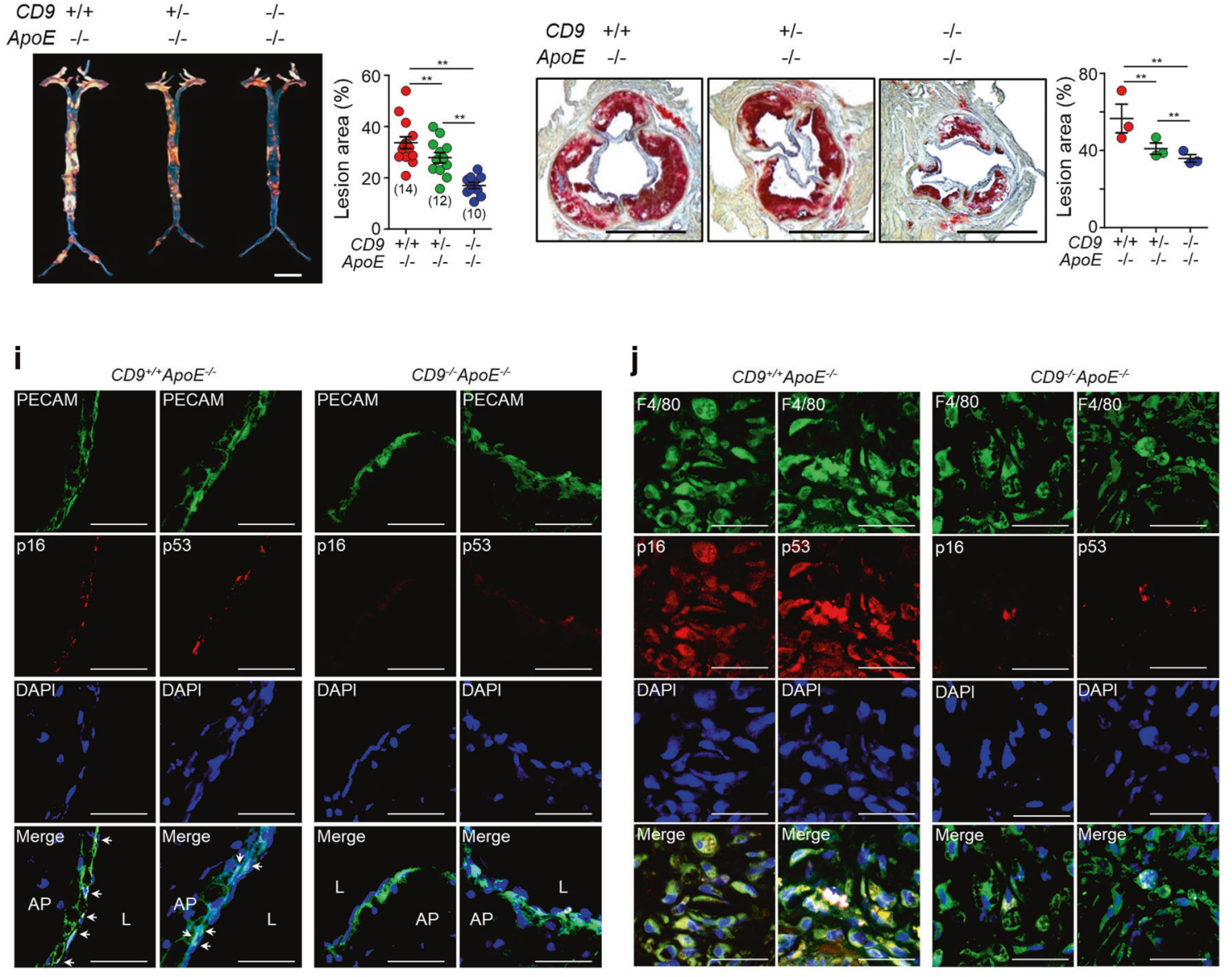

withdrawal of the high-fat diet, the mice were treated with $\alpha \mathrm{rCD} 9$ or $\mathrm{rIgG}$ for 6 weeks and then measured SA $\beta \mathrm{G}$ activity in the aorta en face. We confirmed that treatment with $\alpha \mathrm{rCD} 9$ decreased SA $\beta \mathrm{G}$ activity in atherosclerotic lesions of $\mathrm{Ldll}^{-/-}$mice (Fig. 5f and Supplementary Fig. $\mathrm{S} 5 \mathrm{H})$. These results imply that CD9 blocking antibody 
4 Fig. 5 A CD9 blocking antibody and CD9 depletion alleviate the formation of atherosclerotic lesions in $\mathrm{ApoE}^{-1-}$ mice. a-e $A p o E^{-1-}$ mice fed a high-fat diet were treated with $100 \mu \mathrm{g}$ of $\alpha \mathrm{rCD} 9$ or $\mathrm{rgG}$ every 3.5 days for 15 weeks, and sacrificed. The formation of atherosclerotic lesions in aorta en face and aortic sinuses was analyzed by Oil-red $O$ and $S A \beta G$ staining. a Oil-red $O$ staining (red) and SA $\beta G$ staining (blue) in aortic arches. Scale bar: $1 \mathrm{~mm}$. b SA $\mathrm{SG}$ staining (blue) and SA $\beta$ G positive area (\%) in aorta en face. Scale bar: $5 \mathrm{~mm}$. c Frozen tissue sections $(20 \mu \mathrm{m} / \mathrm{section})$ were prepared from arterial regions indicated with arrows in $\mathbf{b}$, counterstained with eosin, and further analyzed for SA $\beta \mathrm{G}$ staining $(n=5)$. c SA $\beta \mathrm{G}$ staining (blue) and SA $\beta G$ positive area $(\%)$ in atheroma in the arterial tissues $(n=5)$. Scale bar: $100 \mu \mathrm{m}$. d Oil-red O staining (red), CD9 immunoreactivity (brown), SABG staining (blue), and the volume of atherosclerotic lesion in aortic sinuses of $A p o E^{-1-}$ mice $(n=3)$. Scale bar: $500 \mu \mathrm{m}$. e Expression levels of pAKT, p53, p21, p16, CD9, and pS6K proteins in aortas with atherosclerotic lesions. f $L d l r^{-1-}$ mice were fed with a high-fat diet for 4 weeks. After withdrawal of a high-fat diet, the mice were treated with $100 \mu \mathrm{g}$ of $\alpha \mathrm{rCD} 9$ or rIgG every 3.5 days for 6 weeks, and sacrificed. f SA $\beta \mathrm{G}$ staining (blue) in aorta en face $(n=3)$. Scale bar: $5 \mathrm{~mm}$. g-j Male mice of $C D 9^{+/+} A p o E^{-/-}, C D 9^{+/-} A p o E^{-/-}$, and $C D 9^{-/-} \mathrm{ApoE}^{-/-}$were fed a high-fat diet for 9-14 weeks and then sacrificed. The formation of atherosclerotic lesions in aorta en face and aortic sinuses was analyzed by Oil-red O staining. The levels of p16, p53, PECAM, and F4/80 proteins were analyzed in frozen tissue sections using immunofluorescence staining. g Oil-red O staining (red) in aorta en face. Scale bar: $5 \mathrm{~mm}$. Animal numbers are indicated in the parenthesis. h Oil-red $\mathrm{O}$ staining (red) of atherosclerotic lesion in aortic sinuses $(n=3)$. Scale bar: $1 \mathrm{~mm}$. i Immunofluorescence staining of $\mathrm{p} 16, \mathrm{p} 53$, and PECAM in the atherosclerotic lesions. Arrows indicate nuclear staining of p16 and p53. Scale bar: $30 \mu \mathrm{m}$. j Immunofluorescence staining of p16, p53, and F4/80 in the atherosclerotic lesions. Scale bar: $30 \mu \mathrm{m}$. Representative images are shown. Values are the means \pm SE. $\alpha \mathrm{rCD} 9$ a rat monoclonal antibody against mouse $\mathrm{CD}$, rIgG rat IgG, Cont aorta without atheroma, H/E hematoxylineosin staining, AP atherosclerotic plaque, L lumen of artery; $* p<0.05$ and $* * p<0.01$.

might inhibit the formation of atherosclerotic lesions in mice and be beneficial for the development of therapeutics.

To confirm the role of CD9 in atherosclerotic plaque formation, we prepared $\mathrm{CD} 9^{+/+} \mathrm{ApoE}^{-/-}, \mathrm{CD}^{+/-} \mathrm{ApoE}^{-/-}$, and $C D 9^{-/-} \mathrm{ApoE}^{-/-}$mice by crossing $\mathrm{CD} 9^{-/-}$mice and $A p o E^{-/}$mice (Supplementary Fig. S5I), and analyzed atherosclerotic plaque formation in aorta and aortic sinus after feeding them a high-fat diet. No differences in body weight (Supplementary Fig. S5I), and food intake (data not shown) were observed among them. $C D 9$ depletion in $A p o E^{-/-}$mice decreased atherosclerotic lesions in aorta (Fig. 5g and Supplementary Fig. S5J) and aortic sinus (Fig. 5h and Supplementary Fig. S5K). Although CD9 depletion reduced the levels of total cholesterol and LDL cholesterol, no statistical significances was observed (Supplementary Fig. S5L). In addition, $C D 9$ ablation decreased atherosclerotic lesion in male mice fed normal chow diet (Supplementary Fig. S5M). CD9 ablation reduced the p53 and p16 expression in endothelial cells as well as macrophages of atherosclerotic lesions (Fig. 5i-j and Supplementary Fig. S5N, O), suggesting that CD9 increases senescent cell burden in atherosclerotic lesions. Taken together, these data implicate that CD9 might aggravate atherosclerotic plaque formation by increasing senescent cell burden in $A p o E^{-/-}$mice.

\section{Discussion}

CD9 has been reported to be involved in a variety of physiological and pathological processes, including fertilization, infectious diseases, cell proliferation, apoptosis, adhesion, migration, cell differentiation, and tumor malignancy. However, to the best of our knowledge, this is the first report of the roles of CD9 in endothelial cell senescence and atherosclerotic plaque formation. We clearly demonstrated that CD9 plays a critical role in the regulation of cellular senescence in HUVECs specifically; (i) $C D 9$ knockdown in senescent cells significantly rescues senescence phenotypes, and (ii) CD9 upregulation in young cells accelerates cellular senescence, and that CD9 levels were upregulated in age-related vascular pathology.

The results of the present study suggested that CD9 might regulate cellular senescence via the PI3K-AKT-mTOR-p53 pathway without DDR and p16 activation. Our data showed that no activation of DDR occurred in CD9-mediated cellular senescence, although activation of p53 might be involved. Specifically, (i) CD9 upregulation in young cells did not elevate the levels of pATM, an activated form of ATM and $\gamma \mathrm{H} 2 \mathrm{AX}$ DNA damage foci in the nucleus, and (ii) ATM knockdown had no effect on CD9-induced cellular senescence. A variety of genes, including IGFBP3 [47], IGFBP5 [48], and PATZ1 [49], have been reported to regulate cellular senescence in human primary cells through a p53 pathway. DDR is commonly involved in replicative senescence by telomere attrition, oncogene-induced senescence, and stressinduced premature senescence by ionizing radiation and chemotherapeutic agents [3]. However, DDR activation is not a universal feature of cellular senescence. In murine fibroblasts, overexpression of oncogenic Ras induced cell senescence without DDR [50]. Activation of PI3K/AKT in human fibroblasts also induced cellular senescence through mTOR and p53 without DDR and p16 activation [40]. In addition, the PI3K/AKT pathway might be involved in CD9-induced increases in proliferation of VSMCs [21] and cell motility of CHO cells [51], although CD9 influences diverse signal transduction pathways, depending on cell types and the nature of CD9 complex members.

We found that CD9-induced cellular senescence is repressed by PIK3CA knockdown, but not by PIK3CB knockdown, implicating that PIK3CA and PIK3CB might play distinct roles in the regulation of CD9-mediated cellular senescence in human primary cells. Although PIK3CA and PIK3CB are involved in the activation of AKT through 
PI3K signaling, different roles of two isoforms in cellular signaling, metabolism, development, and tumorigenesis were suggested. PIK3CA is critical to regulation of hepatic and hypothalamic insulin action, glucose homeostasis, and energy expenditure [52]. PIK3CB, not PIK3CA, inhibited mouse embryonic stem cell (mESC) differentiation, suggesting that PI3Ks contribute to the regulation of both mESC pluripotency and proliferation by differential coupling to selected PI3K catalytic isoforms [53]. While genetic ablation of PIK3CA blocked breast tumor formation in mouse models, PIK3CB ablation increased ductal branching and tumorigenesis [54]. In addition, PIK3CB, not PIK3CA, induced tumor formation in PTEN null cancer cells [55], implicating differential roles of PIK3CA and PIK3CB in tumorigenesis. Although both PIK3CA and PIK3CB contribute to IGF-1-mediated AKT phosphorylation, inhibition of PIK3CA, but not PIK3CB, blocked IGF1-mediated potentiation of integrin activation and alphagranule secretion in platelets [56].

In addition to in vitro evidence for the regulation of CD9 in cellular senescence, we demonstrated that CD9 increases senescent cell burden in atherosclerotic lesions in mouse models and inhibition or ablation of CD9 reduces the formation of atherosclerotic plaque through the reduction of senescent cell burden. We confirmed that a neutralizing antibody against mouse CD9 alleviated atherosclerotic plaque formation in $\mathrm{ApoE}^{-/-}$mice and $\mathrm{Ldlr}^{-/-}$mice. CD9 interacts with $\mathrm{CD} 36$, a scavenger receptor binding to oxLDL, on the surface of macrophages [57]. CD36 binding to oxLDL accelerates macrophage foam cell formation, which is involved in the formation of atherosclerotic plaques [58]. Therefore, CD9 binding to its specific antibodies might repress its association with $\mathrm{CD} 36$, resulting in inhibition of oxLDL uptake and prevention of atherosclerotic lesion formation in $\mathrm{ApoE}^{-/-}$mice. CD9 levels are upregulated in agerelated vascular pathologies, such as neointima hyperplasia [21] and human atherosclerotic lesions [23], as well as agerelated diseases, such as ovariectomy-induced osteoporosis and collagen-induced arthritis [24]. A neutralizing anti-mouse CD9 antibody inhibited neointima formation in a mouse carotid ligation injury model [21]. Moreover, a CD9 antibody inhibited tumor progression in mice bearing human gastric cancer xenografts via antiproliferative, proapoptotic, and antiangiogenetic effects [59], as well as in platelet-induced human endothelial cell proliferation [60]. Therefore, modulation of CD9 function with CD9-specific antibodies might be a novel strategy for the prevention and treatment of vascular aging, as well as atherosclerosis.

Senescent cells show increased expression of a variety of intracellular or secreted proteins, such as p53, p16, IL-1 $\beta$, or IL-6, which have been used as surrogate markers for cellular senescence. Recently, several proteins associated with the plasma membrane, including DEP1, NTAL, EBP50, and
DCR2, were identified from senescent human fibroblasts and cancer cells; therefore, an attempt was made to apply these as markers for detection of cellular senescence [61]. Since CD9 is a member of the tetraspanin family of membrane proteins and our study clearly demonstrated its roles in cellular senescence, CD9 might be useful as a novel surrogate marker for cellular senescence and provide a novel strategy for the development of diagnostics and therapeutics for tissue aging and age-related diseases. CD9 is also localized in exosomes, which are cell-derived vesicles with a diameter of $30-100 \mathrm{~nm}$ present in a variety of biological fluids, blood and urine; accordingly, CD9 is commonly used as an exosomal marker [62]. Since exosomal proteins are also recognized as potential diagnostic markers of diverse human diseases [63-65], CD9 in exosomes from body fluids might be a novel target for the development of diagnostics for tissue and age-related diseases.

Our findings that $C D 9$ depletion in $A p o E^{-/-}$mice decreased atherosclerotic lesions in both male and female mice suggest that CD9-induced cellular senescence might play a critical role in the regulation of atherosclerosis. Consistently, senescent intimal foam cells were reported to contribute to all stages of atherosclerosis and their elimination by transgenic and pharmacological approaches mitigated atheroma formation, suggesting that selective clearance of senescent cells might be the novel therapeutic strategy against atherosclerosis [6].

In conclusion, our study revealed a previously unknown, but fundamentally important function of CD9 as a potent factor controlling endothelial cell senescence and atherosclerosis. We propose that inhibition of CD9-induced cellular senescence might provide a novel strategy for prevention and treatment of atherosclerosis.

Acknowledgements We thank G.J. Kim at Tae Kyung College for technical assistance. This work was supported by the Basic Science Research Program (2014R1A2A2A01004559), Medical Research Center Program (2015R1A5A2009124), and Bio and Medical Technology Development Program (2013M3A9B6076413) through the National Research Foundation of Korea (NRF) funded by the Ministry of Science and ICT.

\section{Compliance with ethical standards}

Conflict of interest The authors declare that they have no conflict of interest.

Publisher's note Springer Nature remains neutral with regard to jurisdictional claims in published maps and institutional affiliations.

\section{References}

1. Munoz-Espin D, Canamero M, Maraver A, Gomez-Lopez G, Contreras J, Murillo-Cuesta S, et al. Programmed cell senescence during mammalian embryonic development. Cell. 2013; 155:1104-18. 
2. van Deursen JM. The role of senescent cells in ageing. Nature. 2014;509:439-46.

3. Kuilman T, Michaloglou C, Mooi WJ, Peeper DS. The essence of senescence. Genes Dev. 2010;24:2463-79.

4. Rodier F, Campisi J. Four faces of cellular senescence. J Cell Biol. 2011;192:547-56.

5. Wang J, Uryga AK, Reinhold J, Figg N, Baker L, Finigan A, et al. Vascular smooth muscle cell senescence promotes atherosclerosis and features of plaque vulnerability. Circulation. 2015;132:1909-19.

6. Childs BG, Baker DJ, Wijshake T, Conover CA, Campisi J, van Deursen JM. Senescent intimal foam cells are deleterious at all stages of atherosclerosis. Science. 2016;354:472-7.

7. Minamino T, Komuro I. Vascular aging: insights from studies on cellular senescence, stem cell aging, and progeroid syndromes. Nat Clin Pr Cardiovasc Med. 2008;5:637-48.

8. Hemler ME. Tetraspanin functions and associated microdomains. Nat Rev Mol Cell Biol. 2005;6:801-11.

9. Zhang F, Kotha J, Jennings LK, Zhang XA. Tetraspanins and vascular functions. Cardiovasc Res. 2009;83:7-15.

10. Hemler ME. Targeting of tetraspanin proteins-potential benefits and strategies. Nat Rev Drug Discov. 2008;7:747-58.

11. Powner D, Kopp PM, Monkley SJ, Critchley DR, Berditchevski F. Tetraspanin CD9 in cell migration. Biochem Soc Trans. 2011; 39:563-7.

12. Jennings LK, Crossno JT Jr., Fox CF, White MM, Green CA. Platelet p24/CD9, a member of the tetraspanin family of proteins. Ann N Y Acad Sci. 1994;714:175-84.

13. Le Naour F, Rubinstein E, Jasmin C, Prenant M, Boucheix C. Severely reduced female fertility in CD9-deficient mice. Science. 2000;287:319-21.

14. Miyado K, Yamada G, Yamada S, Hasuwa H, Nakamura Y, Ryu $\mathrm{F}$, et al. Requirement of CD9 on the egg plasma membrane for fertilization. Science. 2000;287:321-4.

15. Wang HX, Li Q, Sharma C, Knoblich K, Hemler ME. Tetraspanin protein contributions to cancer. Biochem Soc Trans. 2011;39:547-52.

16. Zoller M. Tetraspanins: push and pull in suppressing and promoting metastasis. Nat Rev Cancer. 2009;9:40-55.

17. van Spriel AB. Tetraspanins in the humoral immune response. Biochem Soc Trans. 2011;39:512-7.

18. Koberle M, Kaesler S, Kempf W, Wolbing F, Biedermann T. Tetraspanins in mast cells. Front Immunol. 2012;3:106.

19. Thali M. Tetraspanin functions during HIV-1 and influenza virus replication. Biochem Soc Trans. 2011;39:529-31.

20. Kim TW, Kim HJ, Lee C, Kim HY, Baek SH, Kim JH, et al. Identification of replicative senescence-associated genes in human umbilical vein endothelial cells by an annealing control primer system. Exp Gerontol. 2008;43:286-95.

21. Kotha J, Zhang C, Longhurst CM, Lu Y, Jacobs J, Cheng Y, et al. Functional relevance of tetraspanin CD9 in vascular smooth muscle cell injury phenotypes: a novel target for the prevention of neointimal hyperplasia. Atherosclerosis. 2009;203:377-86.

22. Lijnen HR, Lupu F, Collen D, Le Naour F, Boucheix C. CD9 gene deficiency does not affect smooth muscle cell migration and neointima formation after vascular injury in mice. Thromb Haemost. 2000;83:956-61.

23. Nishida M, Miyagawa J, Yamashita S, Higashiyama S, Nakata A, Ouchi $\mathrm{N}$, et al. Localization of $\mathrm{CD}$, an enhancer protein for proheparin-binding epidermal growth factor-like growth factor, in human atherosclerotic plaques: possible involvement of juxtacrine growth mechanism on smooth muscle cell proliferation. Arterioscler Thromb Vasc Biol. 2000;20:1236-43.

24. Iwai K, Ishii M, Ohshima S, Miyatake K, Saeki Y. Abundant expression of tetraspanin CD9 in activated osteoclasts in ovariectomy-induced osteoporosis and in bone erosions of collagen-induced arthritis. Rheumatol Int. 2008;28:225-31.
25. Itahana K, Campisi J, Dimri GP. Methods to detect biomarkers of cellular senescence: the senescence-associated beta-galactosidase assay. Methods Mol Biol. 2007;371:21-31.

26. Park KH, Shin DG, Kim JR, Cho KH. Senescence-related truncation and multimerization of apolipoprotein A-I in high-density lipoprotein with an elevated level of advanced glycated end products and cholesteryl ester transfer activity. J Gerontol A Biol Sci Med Sci. 2010;65:600-10.

27. Havel RJ, Eder HA, Bragdon JH. The distribution and chemical composition of ultracentrifugally separated lipoproteins in human serum. J Clin Investig. 1955;34:1345-53.

28. Esterbauer H, Striegl G, Puhl H, Rotheneder M. Continuous monitoring of in vitro oxidation of human low density lipoprotein. Free Radic Res Commun. 1989;6:67-75.

29. Park KH, Cho KH. High-density lipoprotein (HDL) from elderly and reconstituted HDL containing glycated apolipoproteins A-I share proatherosclerotic and prosenescent properties with increased cholesterol influx. J Gerontol A Biol Sci Med Sci. 2011;66:511-20.

30. Beattie JH, Duthie SJ, Kwun IS, Ha TY, Gordon MJ. Rapid quantification of aortic lesions in $\mathrm{ApoE}^{-/-}$mice. J Vasc Res. 2009;46:347-52.

31. Yu CC, Woods AL, Levison DA. The assessment of cellular proliferation by immunohistochemistry: a review of currently available methods and their applications. Histochem J. 1992;24: 121-31.

32. Wagner M, Hampel B, Bernhard D, Hala M, Zwerschke W, Jansen-Durr P. Replicative senescence of human endothelial cells in vitro involves G1 arrest, polyploidization and senescenceassociated apoptosis. Exp Gerontol. 2001;36:1327-47.

33. Akhtar N, Dickerson EB, Auerbach R. The sponge/Matrigel angiogenesis assay. Angiogenesis. 2002;5:75-80.

34. Boisen L, Drasbek KR, Pedersen AS, Kristensen P. Evaluation of endothelial cell culture as a model system of vascular ageing. Exp Gerontol. 2010;45:779-87.

35. Hirao A, Kong YY, Matsuoka S, Wakeham A, Ruland J, Yoshida $\mathrm{H}$, et al. DNA damage-induced activation of p53 by the checkpoint kinase Chk2. Science. 2000;287:1824-7.

36. Banin S, Moyal L, Shieh S, Taya Y, Anderson CW, Chessa L, et al. Enhanced phosphorylation of p53 by ATM in response to DNA damage. Science. 1998;281:1674-7.

37. Lobrich M, Shibata A, Beucher A, Fisher A, Ensminger M, Goodarzi AA, et al. gammaH2AX foci analysis for monitoring DNA double-strand break repair: strengths, limitations and optimization. Cell Cycle. 2010;9:662-9.

38. Yu SW, Wang H, Poitras MF, Coombs C, Bowers WJ, Federoff HJ, et al. Mediation of poly(ADP-ribose) polymerase1-dependent cell death by apoptosis-inducing factor. Science. 2002;297:259-63.

39. Ben-Porath I, Weinberg RA. The signals and pathways activating cellular senescence. Int J Biochem Cell Biol. 2005;37:961-76.

40. Astle MV, Hannan KM, Ng PY, Lee RS, George AJ, Hsu AK, et al. AKT induces senescence in human cells via mTORC1 and p53 in the absence of DNA damage: implications for targeting mTOR during malignancy. Oncogene. 2012;31:1949-62.

41. Manning BD, Cantley LC. AKT/PKB signaling: navigating downstream. Cell. 2007;129:1261-74.

42. Vlahos CJ, Matter WF, Hui KY, Brown RF. A specific inhibitor of phosphatidylinositol 3-kinase, 2-(4-morpholinyl)-8-phenyl-4H-1benzopyran-4-one (LY294002). J Biol Chem. 1994;269:5241-8.

43. Sabatini DM. mTOR and cancer: insights into a complex relationship. Nat Rev Cancer. 2006;6:729-34.

44. Courtney KD, Corcoran RB, Engelman JA. The PI3K pathway as drug target in human cancer. J Clin Oncol. 2010;28:1075-83.

45. Hong HY, Lee HY, Kwak W, Yoo J, Na MH, So IS, et al. Phage display selection of peptides that home to atherosclerotic plaques: 
IL-4 receptor as a candidate target in atherosclerosis. J Cell Mol Med. 2008;12:2003-14.

46. Plump AS, Smith JD, Hayek T, Aalto-Setala K, Walsh A, Verstuyft JG, et al. Severe hypercholesterolemia and atherosclerosis in apolipoprotein E-deficient mice created by homologous recombination in ES cells. Cell. 1992;71:343-53.

47. Kim KS, Kim MS, Seu YB, Chung HY, Kim JH, Kim JR. Regulation of replicative senescence by insulin-like growth factorbinding protein 3 in human umbilical vein endothelial cells. Aging Cell. 2007;6:535-45.

48. Kim KS, Seu YB, Baek SH, Kim MJ, Kim KJ, Kim JH, et al. Induction of cellular senescence by insulin-like growth factor binding protein-5 through a p53-dependent mechanism. Mol Biol Cell. 2007;18:4543-52.

49. Cho JH, Kim MJ, Kim KJ, Kim JR. POZ/BTB and AT-hookcontaining zinc finger protein 1 (PATZ1) inhibits endothelial cell senescence through a p53 dependent pathway. Cell Death Differ. 2012;19:703-12.

50. Efeyan A, Murga M, Martinez-Pastor B, Ortega-Molina A, Soria $\mathrm{R}$, Collado M, et al. Limited role of murine ATM in oncogeneinduced senescence and p53-dependent tumor suppression. PLoS ONE. 2009;4:e5475.

51. Kotha J, Longhurst C, Appling W, Jennings LK. Tetraspanin CD9 regulates beta 1 integrin activation and enhances cell motility to fibronectin via a PI-3 kinase-dependent pathway. Exp Cell Res. 2008;314:1811-22.

52. Sopasakis VR, Liu P, Suzuki R, Kondo T, Winnay J, Tran TT, et al. Specific roles of the p110alpha isoform of phosphatidylinsositol 3-kinase in hepatic insulin signaling and metabolic regulation. Cell Metab. 2010;11:220-30.

53. Kingham E, Welham M. Distinct roles for isoforms of the catalytic subunit of class-IA PI3K in the regulation of behaviour of murine embryonic stem cells. J Cell Sci. 2009;122:2311-21.

54. Utermark T, Rao T, Cheng H, Wang Q, Lee SH, Wang ZC, et al. The p110alpha and p110beta isoforms of PI3K play divergent roles in mammary gland development and tumorigenesis. Genes Dev. 2012;26:1573-86.
55. Wee S, Wiederschain D, Maira SM, Loo A, Miller C, deBeaumont R, et al. PTEN-deficient cancers depend on PIK3CB. Proc Natl Acad Sci USA. 2008;105:13057-62.

56. Blair TA, Moore SF, Williams CM, Poole AW, Vanhaesebroeck B, Hers I. Phosphoinositide 3-kinases p110alpha and p110beta have differential roles in insulin-like growth factor-1-mediated Akt phosphorylation and platelet priming. Arterioscler Thromb Vasc Biol. 2014;34:1681-8.

57. Huang W, Febbraio M, Silverstein RL. CD9 tetraspanin interacts with $\mathrm{CD} 36$ on the surface of macrophages: a possible regulatory influence on uptake of oxidized low density lipoprotein. PLoS ONE. 2011;6:e29092.

58. Febbraio M, Hajjar DP, Silverstein RL. CD36: a class B scavenger receptor involved in angiogenesis, atherosclerosis, inflammation, and lipid metabolism. J Clin Investig. 2001;108:785-91.

59. Nakamoto T, Murayama Y, Oritani K, Boucheix C, Rubinstein E, Nishida $M$, et al. A novel therapeutic strategy with anti-CD9 antibody in gastric cancers. J Gastroenterol. 2009;44:889-96.

60. Ko EM, Lee IY, Cheon IS, Kim J, Choi JS, Hwang JY, et al. Monoclonal antibody to CD9 inhibits platelet-induced human endothelial cell proliferation. Mol Cells. 2006;22:70-77.

61. Althubiti M, Lezina L, Carrera S, Jukes-Jones R, Giblett SM, Antonov A, et al. Characterization of novel markers of senescence and their prognostic potential in cancer. Cell Death Dis. 2014;5:e1528.

62. Colombo M, Raposo G, Thery C. Biogenesis, secretion, and intercellular interactions of exosomes and other extracellular vesicles. Annu Rev Cell Dev Biol. 2014;30:255-89.

63. Street JM, Birkhoff W, Menzies RI, Webb DJ, Bailey MA, Dear JW. Exosomal transmission of functional aquaporin 2 in kidney cortical collecting duct cells. J Physiol. 2011;589:6119-27.

64. Gonzalez-Calero L, Martin-Lorenzo M, Alvarez-Llamas G. Exosomes: a potential key target in cardio-renal syndrome. Front Immunol. 2014;5:465.

65. Jakobsen KR, Paulsen BS, Baek R, Varming K, Sorensen BS, Jorgensen MM. Exosomal proteins as potential diagnostic markers in advanced non-small cell lung carcinoma. J Extracell Vesicles. 2015;4:26659. 